\title{
Advancing a Biopsychosocial and Contextual Model of Sleep in Adolescence: A Review and Introduction to the Special Issue
}

\author{
Stephen P. Becker $\cdot$ Joshua M. Langberg $•$ \\ Kelly C. Byars
}

Received: 19 December 2014/ Accepted: 23 December 2014/Published online: 1 January 2015

(C) Springer Science+Business Media New York 2014

\begin{abstract}
Sleep problems in adolescence have been identified as an international public health issue. Over the past few decades, notable advances have been made in our understanding of the patterns and consequences of sleep in adolescence. Despite these important gains, there is much about the role of sleep in adolescence that remains to be understood. This Special Issue brings together studies that examine sleep as it specifically pertains to adolescent development and adjustment. In this introductory article, we argue for the importance of grounding the study of sleep and adolescence in developmental science and a developmental psychopathology framework. First, a review of the literature is used to outline a biopsychosocial and contextual model of sleep in adolescence. Second, attention-deficit/hyperactivity disorder (ADHD) is used as an exemplar of the proposed model given the pervasiveness of sleep problems among youth with ADHD and the likelihood that sleep problems and ADHD symptoms are interconnected in complex ways. Finally, a brief introduction to
\end{abstract}

S. P. Becker $(\varangle) \cdot$ K. C. Byars

Division of Behavioral Medicine and Clinical Psychology,

Department of Pediatrics, Cincinnati Children's Hospital

Medical Center, 3333 Burnet Avenue, MLC 10006, Cincinnati,

OH 45229, USA

e-mail: stephen.becker@cchmc.org

S. P. Becker · K. C. Byars

Department of Pediatrics, University of Cincinnati College of

Medicine, Cincinnati, OH, USA

J. M. Langberg

Department of Psychology, Virginia Commonwealth University, Richmond, VA, USA

K. C. Byars

Division of Pulmonary Medicine, Cincinnati Children's Hospital Medical Center, Cincinnati, OH, USA the empirical articles included in the Special Issue is provided, with particular attention given to how these articles fit within the proposed biopsychosocial and contextual model. Along with the framework proposed in this article, the studies included in this Special Issue advance the current literature and point to critical directions for future research.

Keywords Adolescent - Attention-deficit/hyperactivity disorder · Developmental psychopathology · Hyperkinetic disorder $\cdot$ School start time $\cdot$ Sleep problems

\section{Introduction}

Sleep problems in adolescence are recognized as an international public health concern (American Academy of Pediatrics 2014; Gradisar et al. 2011). Strictly defining sleep in terms of duration, approximately $60 \%$ of middle school students in the United States (US) sleep less than the recommended $9 \mathrm{~h}$ per night on school nights and this figure rises to $87.5 \%$ among ninth grade students and to $95 \%$ by the end of high school (Eaton et al. 2010; National Sleep Foundation 2006). Specifically, whereas 13-year-olds obtain an average of $8.5 \mathrm{~h}$ of sleep per school night, this declines across adolescence such that 17 -year-olds obtain an average of $7.5 \mathrm{~h}$ of sleep per school night (Maslowsky and Ozer 2014). Although reducing sleep duration by a single hour may seem inconsequential, it is clear that even $1 \mathrm{~h}$ of reduced sleep duration has a negative impact on youth's functioning (Gillen-O'Neel et al. 2013; Sadeh et al. 2003). Moreover, this decline in school night sleep duration stands in stark contrast to studies showing that during the period of adolescence when brain maturation processes are occurring, approximately $9 \mathrm{~h}$ of sleep per night is 
considered optimal (Carskadon et al. 1980). As noted by Dahl and Lewin (2002), "Whatever its purpose, sleep seems to be particularly important during periods of brain maturation. Across species, greater sleep requirements are observed in maturing versus fully mature individuals" ( $\mathrm{p}$. 176).

Given the pervasiveness of sleep problems in adolescence and clear relevance for public health, this Special Issue was assembled in an effort to further advance the empirical knowledge regarding the role of sleep in adolescent development and adjustment. ${ }^{1}$ In this introductory article, a biopsychosocial and contextual model of sleep in adolescent development is described in order to provide a backdrop to the articles included in this Special Issue in addition to offering a theoretical framework for future research focused on the study of sleep in adolescence. Our hope is that the proposed model builds on other recent reviews (e.g., Beebe 2011; Carskadon 2011) in advocating for an empirical study of sleep in adolescence that is grounded in developmental science and a developmental psychopathology framework in order to elucidate an increasingly integrated and fine-tuned understanding of the role of sleep across adolescence. Given the pervasiveness of sleep problems among youth with attention-deficit/ hyperactivity disorder (ADHD) and the likelihood that sleep problems and ADHD symptoms are interconnected in complex ways, ADHD is offered as an exemplar of the proposed model in highlighting some of the complex and critical questions that remain to be addressed. Finally, we briefly review the empirical articles included in this Special Issue and note in particular how these articles advance an integrated approach to the study of sleep in adolescence.

\section{A Biopsychosocial and Contextual Model of Sleep in Adolescence}

There is much about the crucible of adolescence that makes it especially susceptible to disruptions in sleep. In addition to many biological changes that occur during this developmental stage, adolescents are confronted with shifting family and peer relationships, increased academic demands, and an overarching change in the daily milieu that now includes not only school and extracurricular activities but also, for many teens, part-time employment, pervasive use of technology, and decisions on health-

\footnotetext{
${ }^{1}$ Note that this Special Issue (including this introductory article) focuses on sleep functioning and problems often experienced by adolescents broadly and does not focus on sleep disorders or adolescents with diagnosed sleep disorders.
}

related behaviors such as driving and substance use. As such, the study of sleep in adolescence cannot resort to the happenstance of having data collected from youth in the second decade of life, but rather, must consider the unique developmental changes and challenges that typify the adolescent period. It is with this goal in mind that we aim to advance an increasingly integrated biopsychosocial and contextual framework to the study of sleep in adolescence. A schematic of this model is displayed in Fig. 1. As shown, and not unlike Bronfenbrenner's (1979, 1992) ecological model of development, we consider sleep to be interwoven with the biological, psychosocial, and contextual factors of adolescents' lives-not only at any given time but also across development. We acknowledge that the boundaries among these various factors are themselves often porous, but for simplicity, we have tried to delineate them to the extent possible. For example, we acknowledge that family and peer factors are themselves contextual in nature (Collins and Steinberg 2008) but we consider these family and peer factors below as psychosocial factors and retain the term "contextual factors" to refer to broader aspects of adolescents' environment including school, community, and cultural factors. It should also be noted that in our review of the research we prioritized seminal studies and very recent studies that shed light on the many opportunities and challenges encountered when studying sleep within the complexity of adolescence.

\section{Biological Factors}

Borbély's (1982) two-process model of sleep regulation comprised of a homeostatic sleep-wake component (referred to as Process S) and a circadian component (referred to as Process C) is used to guide theory and research of adolescent sleep (see also Borbély and Achermann 1999; Borbély et al. 1989). Briefly, the homeostatic sleep-wake component refers to the increased need to sleep (i.e., sleep pressure), with sleep pressure increasing the longer an individual stays awake and reducing as sleep occurs. In contrast, the circadian component of the twoprocess model is not driven by prior sleep-wake duration but is rather an intrinsic, "internal clock" system responsible for regulating the daily, 24-h rhythmic cycle. The secretion of melatonin, a hormone produced by the pineal gland in humans, is reliably linked to the circadian system (Cajochen et al. 2003; Klerman et al. 2002). These homeostatic sleep-wake and circadian systems ideally work in sync to optimally regulate sleep, but this balance is often disrupted by biological, psychosocial, and contextual changes encountered in adolescence.

In terms of biology, the transition from childhood to adolescence is accompanied by significant neurodevelopmental changes, including brain reorganization and 


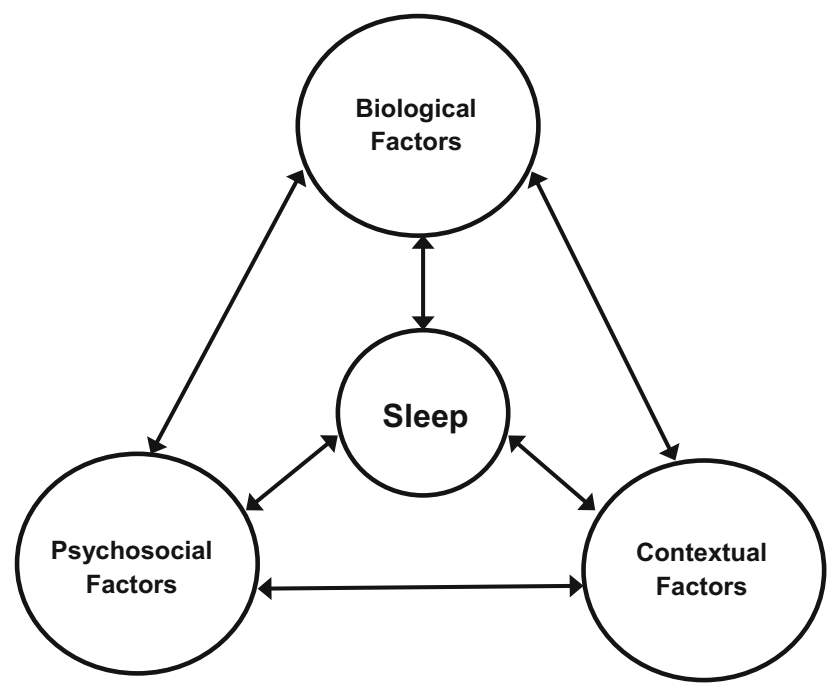

Adolescent Development

Fig. 1 Biopsychosocial and contextual model of sleep in adolescence

synaptic pruning (Sisk and Foster 2004). These changes have an impact on sleep architecture as children enter into adolescence (see Colrain and Baker 2011; Dahl and Lewin 2002 , for reviews). There is a decrease of slow wave sleep across adolescence (Colrain and Baker 2011; Ohayon et al. 2004), with delta power [assessed with sleep electroencephalogram (EEG)] starting to decline notably around age 11 and theta power also showing a steep decline from age 11-16.5 (Campbell and Feinberg 2009). These changes in the adolescent EEG, which align with a decrease in gray matter brain tissue across adolescence, are hypothesized to be due to synaptic pruning that occurs as part of adolescent brain maturation (Campbell and Feinberg 2009; Feinberg and Campbell 2010; Whitford et al. 2007). These changes ultimately impact sleep-wake homeostasis as older, more mature adolescents, are more slow to accumulate sleep pressure (Jenni et al. 2005; Taylor et al. 2005). For example, Taylor et al. (2005) found sleep tendency after extended periods of wakefulness to be lower among mature adolescents (Tanner stage 5) in comparison to prepubertal adolescents (Tanner stage 1), leading the authors to conclude that "a developmental change of intrinsic sleepwake regulation may provide physiologically mediated 'permission' for later bedtimes in older adolescents" ( $p$. 239). That is, adolescence is characterized by an increase in eveningness preference (often described as a shift from being a "morning lark" to an "evening owl"), which is itself linked to pubertal status (Colrain and Baker 2011) and reaches its peak around the age of 20 before beginning its steady decline across adulthood (Roenneberg et al. 2004). This also contributes to a weekend phase delay wherein, starting around age 9 (Thorleifsdottir et al. 2002), many adolescents try to "catch up" on sleep on weekends when the weekday demands requiring an early rise time such as school are less pressing. As described by Dahl and Lewin (2002), "a typical and preferred adolescent summer sleep schedule is 3:00 a.m. to noon" (p. 179). It remains critical for studies of sleep in adolescence to consider these pubertal and neurodevelopmental changes, including a need for more studies that distinguish between age and puberty (e.g., Feinberg et al. 2006; Johnson et al. 2006; Pesonen et al. 2014; Sadeh et al. 2009) in order to tease apart contributions made by chronological age versus (or in interaction with) pubertal development.

Just as biologically-based factors impact sleep in adolescence, it is also increasingly evident that sleep functioning can impact how the human body functions. For example, poor sleep quality is longitudinally associated with an unhealthy heart rate variability pattern (Michels et al. 2013), which may be especially important to consider in studies seeking to elucidate the possible association between sleep and cardiovascular risk factors such as childhood obesity (Cappuccio et al. 2008). In one example of how a biopsychosocial model may be useful in advancing our understanding of the effects of sleep on adolescent adjustment, Telzer et al. (2013) conducted a functional magnetic resonance imaging (fMRI) study in an effort to examine how poor sleep quality influences both brain function and risk taking in adolescence. The authors found that youth reporting poorer sleep had less activation in the dorsolateral prefrontal cortex (DLPFC) during cognitive control, greater insula activation during reward processing, and reduced functional coupling between the DLPFC and affective brain regions. Coupled with behavioral findings showing adolescents who reported poorer sleep to be especially oriented to rewards and less motivated to engage in cognitive control, the authors concluded that "adolescents with poor sleep quality may have both a greater orientation towards risk and compromised decision making abilities" (Telzer et al. 2013, p. 281). This is but one example of the types of studies that are needed to further advance our understanding of the interconnectedness of sleep and brain-behavior associations.

\section{Psychosocial Factors}

There are many psychosocial factors that can influence sleep patterns, and in a reciprocal fashion sleep may in turn impact psychosocial functioning. Family, peer, academic, and mental health factors are discussed below, although, to be sure, these factors are themselves interconnected in complex ways. 


\section{Family Factors}

The family environment has been identified as an important context for understanding sleep across the lifespan (Dahl and El-Sheikh 2007). Although it is clear that the family environment has an important impact on children's sleep functioning (Bartel et al. 2014; Meltzer and MontgomeryDowns 2011), the role of the family environment in promoting adolescents' optimal or disturbed sleep remains poorly understood. Relatedly, as recently reviewed by Adams et al. (2014), extant evidence indicates attachment style may be related to sleep across the life span. However, the vast majority of studies have been conducted with infants or school-aged children and they did not identify any studies conducted with early-to-mid adolescents. Still, available studies suggest that attachment and family environment impact sleep in adolescence. For instance, in a sample of Finnish 15-year-olds, youth perceptions of having a good home atmosphere was strongly correlated with self-reported sleep quality (Tynjala et al. 1999). In studies conducted with college students, a cross-sectional link has been found between insecure attachment and poorer sleep functioning (McNamara et al. 2001; Scharfe and Eldredge 2001). Safety is a critical aspect of attachment bonds and the family environment more broadly also creates the "the state of 'safety' necessary for sleep (and the cessation of vigilance)" (Dahl and El-Sheikh 2007, p. 2). It may be this safety in the family environment that explains the finding that parents' sleep quality correlates with adolescents' sleep quality (Bajoghli et al. 2013; Brand et al. 2009). In addition, there is preliminary (cross-sectional) evidence to suggest that the association between maternal sleep and adolescent sleep is mediated by parenting style and adolescents' psychological functioning (Brand et al. 2009), further underscoring the importance of both the interpersonal and intrapersonal contexts in examining adolescent sleep functioning. Since genetics also influences sleep functioning (Sletten et al. 2013), future research should integrate both family/parenting factors and biological factors in studies examining sleep within the family context.

In addition, parent limit-setting may be important for fostering adolescents' sleep (Bartel et al. 2014). Adolescents with parent-set bedtimes have earlier bedtimes and obtain more nighttime sleep and also experience less fatigue and improved daytime functioning (Short et al. 2011). Adolescents with parent-set bedtimes of 10:00 p.m. or earlier are $24 \%$ less likely to experience depression and $20 \%$ less likely to have suicidal ideation in comparison to adolescents with parent-set bedtimes of midnight or later (Gangwisch et al. 2010). Likewise, in a representative time-diary study of over 2,400 youth in the US, stricter household rules were associated with adolescents obtaining more weekday sleep hours (and an early bedtime); this association was specific to adolescents and not found among children (Adam et al. 2007). Conversely, although not associated with overall sleep duration, parenting styles characterized by restriction, reproach, and inconsistency are associated with adolescents experiencing poorer sleep quality and greater daytime sleepiness (Brand et al. 2009). Greater autonomy and frequent parent-teen conflict both predict a stronger eveningness (vs. morningness) orientation and, of note, these associations remain present after controlling for both pubertal development and chronological age (Diaz-Morales et al. 2014). Interestingly, greater eveningness preference among pre-adolescents and early adolescents is linked to externalizing behaviors in boys and reactive aggression in girls (Susman et al. 2007). These findings are in line with developmental research showing the absence of parental involvement in the decision-making of adolescents is related to an increase in behavior problems (Van Petegem et al. 2012). This is particularly noteworthy since the percentage of adolescents who report having a parent-set bedtime steadily declines from $33 \%$ at age 13 to $0 \%$ at age 18 (Short et al. 2011).

Finally, sleep functioning has recently been identified as an important process by which parent-child conflict contributes to internalizing and externalizing symptoms. In a 3-year longitudinal study, Kelly et al. (2014) found that physical parent-child conflict at age 9 predicted poorer sleep functioning (as measured with actigraphy) at age 10, which in turn predicted internalizing and externalizing symptoms at age 11 . This study is important for several reasons, including a longitudinal design, use of both child/ parent ratings and actigraph measures of sleep, and distinguishing between specific sleep domains (significant effects were specific to sleep efficiency and long nighttime wake episodes and not sleep duration, sleep onset latency, or sleep variability). It also appears that associations are bidirectional in nature, as Bell and Belsky (2008) found that mother-child relationships characterized by less closeness and greater conflict in late childhood were associated with more sleep problems in young adolescence, and childhood sleep problems were likewise associated with decreases in sensitive mothering and closeness over time.

\section{Peer Factors}

Surprisingly few studies have investigated the degree to which adolescent peer relationships affect sleep functioning and vice versa. Extant findings point to the importance of additional studies in this area. Adolescents with sleep problems report experiencing more loneliness than adolescents without sleep problems (Mahon 1994; Xu et al. 2012), and young adolescents with a history of chronic 
loneliness report more sleep problems than their peers (Harris et al. 2013). In a 12-month longitudinal study, Roberts et al. (2002) found that youth with high levels of sleep problems experienced greater problems in their peer relationships, even after controlling for initial levels of peer functioning. More recently, reduced school night sleep duration was associated with greater self-reported peer problems in a sample of 11,788 youth drawn from 11 European countries (Sarchiapone et al. 2014). Moreover, there is evidence that loneliness exacerbates the association between adolescents' self-reported daytime stress and actigraphy-assessed nighttime sleep functioning (Doane and Thurston 2014). An early study in this area found that loneliness was associated with greater sleep problems in early and middle adolescents but not in later adolescents (Mahon 1994), perhaps because of the increasing prioritization of friends as sources of peer support in early/mid-adolescence (Helsen et al. 2000). Indeed, adolescents are more likely to experience loneliness in early adolescence as opposed to late adolescence (Ladd and Ettekal 2013), which may accentuate the experience of social isolation (Laursen and Hartl 2013). Further, loneliness may contribute to increased depressive symptoms and social anxiety (Fontaine et al. 2009; Lasgaard et al. 2011; Storch et al. 2003), which in turn may interfere with optimal sleep functioning. Given the importance of the peer group (and friendship in particular) in adolescence (Bukowski et al. 2011; Collins and Steinberg 2008), peer victimization may contribute to increased daytime stress and/or an adolescent's feelings of loneliness. A recent study found that adolescents who had been victimized had significantly more sleep disturbances in comparison to adolescents who had not been victimized (Kubiszewski et al. 2014). Further, in this same sample, youth classified as bullies showed significantly more irregular sleep patterns and shorter sleep duration than their non-bully peers.

In addition to loneliness and victimization, the amount of time spent with peers also impacts sleep functioning. Fuligni and Hardway (2006) found more time spent with friends each day to be associated with both average sleep duration and variability in sleep duration. Of note, positive peer relationships may have a positive effect on sleep functioning. Maume (2013) found initial positive peer relationships-as well as increases in positive peer relationships over time-to be associated with fewer sleep problems. Increases in positive peer relationships were also associated with longer school night sleep duration (Maume 2013). Thus, extant research suggests that peer relationships may be either risks for or buffers against sleep difficulties in adolescence, and uncovering the processes underlying either of these is an important area for ongoing research.

\section{Mental Health}

Sleep and mental health functioning are clearly intertwined (see Astill et al. 2012, for a meta-analytic review of schoolaged children), and, indeed, disturbed sleep is a symptom of several psychiatric disorders. Although sleep functioning is likely relevant to most, if not all, domains of mental health we limit the scope of our review herein to anxiety, depression, suicidal ideation/behaviors, externalizing behaviors, and substance use (attention problems are covered in more detail below in the section on ADHD). In addition, unless otherwise noted, the studies reviewed in this section focus on dimensional mental health symptomatology and behaviors in community- and school-based samples of youth as opposed to clinic-referred or DSM- or ICD-diagnosed samples.

Depression and Anxiety Considerable research attention has been devoted to understanding the link between sleep functioning and internalizing symptoms such as anxiety and depression. It is clear that shorter sleep duration, poor sleep quality, and daytime sleepiness are concurrently associated with both anxiety and depression in adolescents (e.g., Do et al. 2013; Fuligni and Hardway 2006; KirmilGray et al. 1984; Manni et al. 1997; McKnight-Eily et al. 2011; Moore et al. 2009; Roberts et al. 2001; Sarchiapone et al. 2014; Yen et al. 2010). Given the number of studies that have examined the interrelations of sleep and anxiety/ depression in adolescents, the following review focuses on longitudinal studies in this area.

A number of longitudinal studies have shown sleep problems in childhood or adolescence to confer risk for later depressive symptoms (e.g., Danielsson et al. 2013; Roberts et al. 2002; see Lovato and Gradisar 2014, for a review). For instance, Gregory and O'Connor (2002) conducted an 11-year longitudinal study and found sleep problems at age 4 to predict anxiety/depression symptoms in adolescence, after controlling for toddlerhood levels of anxiety/depression. Of note, the reverse association of anxiety/depression symptoms in toddlerhood predicting sleep problems in adolescence was not supported (Gregory and O'Connor 2002). Fredriksen et al. (2004) also found that young adolescents who obtained less sleep over time also reported higher levels of depressive symptoms and lower self-esteem, whereas depressive symptoms and selfesteem did not predict sleep problems over time. In another study, Gregory et al. (2008) found parent-reported endorsement of children/adolescents (ages 4-19) "sleeping less than others" to predict self-reported anxiety/depression in young adulthood (ages 18-32 years). Similarly, even after controlling for sex and initial levels of depression, Roane and Taylor (2008) found insomnia symptoms in adolescence (ages 12-18 years) to be a significant risk 
factor for having a depression diagnosis 6-7 years later in young adulthood. Last, in a longitudinal, community-based study of 386 youth, childhood sleep problems predicted maternal ratings of internalizing problems in adolescence, with findings similar for boys and girls (Wong et al. 2009).

Experimental and daily diary studies also demonstrate a relation between inadequate or insufficient sleep with depression and mood problems. For instance, sleep restriction resulting in sleep deprivation (either extreme [acute] sleep deprivation or sleep deprivation similar to the everyday sleep duration of many adolescents [chronic partial]) contributes to adolescents experiencing both a reduction in positive affect (Talbot et al. 2010) as well as worsened mood and a decreased ability to regulate negative emotions (Baum et al. 2014). In a daily diary study where adolescents reported on their sleep habits, daily activities (e.g., time spent studying, watching television), and mood each day over a 2-week period, Fuligni and Hardway (2006) found studying and stressful demands during the day to predict less sleep that evening, which in turn was associated with adolescents reporting higher levels of anxiety, depression, and fatigue the next day. Moreover, no evidence was found for daily ratings of anxiety and depression to impact that night's sleep (Fuligni and Hardway 2006), supporting the possibility that sleep has a negative impact on mood/anxiety more so than the reverse.

Despite these findings showing sleep problems to predict depression across observational and experimental studies and in different age ranges and sample types, it is important to note that some exceptions have been reported. In a representative population sample of 1,420 youth (ages 8-14 years), Shanahan et al. (2014) found that depression alone was neither predictive of nor predicted by sleep problems. In contrast, a reciprocal association was found between generalized anxiety and sleep problems: generalized anxiety predicted later sleep problems and sleep problems likewise predicted later generalized anxiety, leading the authors to conclude that "generalized anxiety appeared to be the 'necessary ingredient' for longitudinal associations between internalizing distress disorders and sleep disturbance" (Shanahan et al. 2014, p. 555). Likewise, after controlling for internalizing symptoms in childhood, Gregory et al. (2005) found persistent sleep problems in childhood to predict a diagnosis of anxiety but not depression in young adulthood. Armstrong et al. (2014) similarly found in a 14-year prospective study that persistent parent-reported insomnia in childhood predicted selfreported anxiety symptoms but not depression in adolescence. In considering these findings, the authors suggest that "persistent childhood insomnia may represent subclinical, prodromal precursors of anxiety, perhaps reflecting the beginning of the presleep cognitive arousal and hypervigilance that can lengthen sleep onset and disrupt deep sleep and that also have been theorized to underlie the development of anxiety" (Armstrong et al. 2014, p. 907). Since anxiety and depression are highly correlated and often comorbid, it is important that studies separate anxiety and depression (as opposed to using a composite measure of internalizing symptoms) in order to increase specificity. Interestingly, Danielsson et al. (2013) found that the association between sleep problems and depression was mediated in part by catastrophic worry, pointing to the potential importance of anxiety in understanding the link between sleep and depression in youth.

Ultimately, it is likely that anxiety, depression, and sleep problems are intertwined. Johnson et al. (2006) found anxiety to increase adolescents' risk for insomnia and insomnia increased adolescents' risk for depression. These findings suggest that sleep problems, anxiety, and depression may have cascading effects among each other. It is especially important to consider these associations in adolescence when rates of depression and certain anxieties (e.g., panic disorder) increase (Costello et al. 2011; Lewinsohn et al. 1994). Moreover, the prefrontal cortex (PFC) plays an important role in affect regulation (Ochsner and Gross 2005) and is not fully developed until early adulthood (Giedd 2004; Spear 2000). A recent fMRI study found a non-linear relationship between age and cognitive reappraisal (important for emotion regulation) alongside decreased engagement of several brain regions (including several prefrontal areas) during an emotion regulation task, leading to the conclusion that "adolescents may process the emotional value of stimuli differently than either children or adults" (McRae et al. 2012, p. 17). Such findings are important for understanding the development of mood problems in adolescence. Moreover, since the PFC is not only important for affect regulation but also plays an important role in modulating and mediating sleep functioning (Muzur et al. 2002), studies that incorporate neuroimaging would be tremendously useful for advancing our current knowledge of the interrelations of sleep functioning and internalizing problems across the adolescent period.

Suicidal Ideation and Behavior In line with studies showing sleep problems to be associated with depression, anxiety, and disruptions in affect regulation, investigators have examined whether sleep problems may also confer risk for suicidal ideation and behaviors. Several studies have found poorer sleep functioning to be concurrently associated with adolescent-reported suicidal ideation (Do et al. 2013; Roane and Taylor 2008; Sarchiapone et al. 2014; Yen et al. 2010). In Roane and Taylor's (2008) population-based study, poor sleep was also associated with suicide attempts. Liu (2004) found a similar association, with adolescents who obtained less than $8 \mathrm{~h}$ of sleep per night being at increased risk for attempting suicide, 
even after controlling for age, sex, and depressive symptoms. Interestingly, having frequent nightmares was uniquely linked to both suicidal ideation and suicide attempts (Liu 2004). Using data from the National Longitudinal Study of Adolescent Health (Add Health) study, Wong and Brower (2012) found sleep problems to longitudinally predict suicidal thoughts and suicide attempts, even after controlling for depression, alcohol problems, drug use, and youth characteristics such as age, sex, and chronic health problems. Furthermore, sleep problems are related to suicide completion among adolescents. Specifically, Goldstein et al. (2008) found that adolescents who completed suicide showed more sleep difficulties than comparison adolescents during the week preceding suicide as well as during adolescents' most recent depressive episode.

Sleep problems also have been recently linked to nonsuicidal self-injury (NSSI) among adolescent girls (Lundh et al. 2013). Specifically, $77 \%$ of adolescent girls who indicated that they slept well "seldom" or "never" reported engaging in NSSI 1 year later. Moreover, poor sleep at the initial study time-point predicted the incidence of new cases of NSSI at the 1-year follow-up, even after accounting for baseline levels of general psychopathology symptoms, although this association was found only for girls and not for boys (Lundh et al. 2013). Other studies are needed to replicate this finding. There is likewise a need for future studies in this area to also consider other important factors such as family functioning (Wilkinson et al. 2011) and peer influences (Prinstein et al. 2010) to more fully determine whether sleep problems have a unique effect on adolescents' NSSI, suicidal ideation, and suicidal behaviors.

Externalizing Behaviors In comparison to internalizing mental health symptoms, fewer studies have examined the role of sleep in relation to adolescents' externalizing behavior problems. Nonetheless, extant studies demonstrate sleep functioning to be associated with aggression and other externalizing behavior problems in adolescence. In a sample of detained adolescent and young adult males (ages 14-20 years), Ireland and Culpin (2006) found shorter sleep duration and poorer sleep quality to be concurrently associated with increased trait aggression. In a longitudinal study, Gregory and O'Connor (2002) found sleep problems at age 4 to predict aggressive behaviors in adolescence, but no evidence was found to support the reverse relation. Likewise, Gregory et al. (2008) also found that parent-reported sleep problems longitudinally predicted self-reported aggression in young adulthood. Of note, it appears that sleep problems are more closely associated with reactive aggression as opposed to proactive aggression in adolescence (Fite et al. 2014). In considering externalizing problems more broadly, Armstrong et al. (2014) found persistent parent-reported insomnia in childhood to significantly predict self-reported externalizing problems in adolescence. In the study by Shanahan et al. (2014) described above, sleep problems both predicted and were predicted by oppositional defiant disorder (ODD), even after controlling for youth characteristics and comorbid psychiatric disorders. In addition, the bidirectional longitudinal associations with sleep problems were unique to oppositionality, as neither conduct disorder nor substance use disorders were longitudinally associated with sleep problems (Shanahan et al. 2014). Wong et al. (2009) also found childhood sleep problems to longitudinally predict externalizing behaviors in adolescence. Experimental studies using sleep restriction protocols also provide evidence linking sleep deprivation to increased oppositionality and irritability in adolescence (Beebe et al. 2008). Finally, eveningness is associated with increased sensation seeking in adolescence (Muro et al. 2012) and there is some evidence to suggest that having an eveningness preference is associated with externalizing behaviors. Specifically, Susman et al. (2007) found that having an eveningness (vs. morningness) preference in late childhood/early adolescence (ages 8-13 years) was associated with antisocial behavior for boys but not girls, whereas an eveningness preference was uniquely associated with reactive aggression for girls but not boys.

It is important to note that not all studies have found an association between sleep functioning and adolescent behavior problems. In a cross-sectional study of 247 adolescents, actigraphy-measured sleep duration/sleep variability and youth-reported daytime sleepiness were not associated with parent- and teacher-reported externalizing problems (Moore et al. 2009). In addition, a recent study by Lemola et al. (2012) offers an example of how an integrated approach to studying sleep in adolescence may be used to identify important ways in which sleep may exacerbate or buffer developmental associations. Specifically, the investigators conducted a multi-informant study in 176 young adolescents (ages 10-13 years) to examine whether youth self-reported sleep problems moderated the association between parent-rated interparental conflict and youth self-reported aggression. Although a direct association between sleep and aggression was not found, poorer sleep functioning exacerbated the association between interparental conflict and youth aggression. These findings highlight the importance of considering moderators of associations, including sleep as a potential moderator, as well as consideration of factors that may moderate the effects of sleep on adjustment.

Delinquency and Substance Use Although it was noted above that few studies have examined the direct effect of 
sleep functioning on peer relationships, a larger body of research has examined the effects of sleep on outcomes often linked to the peer group such as substance use and delinquency. In regards to the association between sleep and delinquency, mixed findings have been reported. Clinkinbeard et al. (2011) found that youth obtaining 7 or fewer hours of sleep per night reported more property delinquency than youth obtaining 8-10 h of sleep. Further, youth obtaining 5 or fewer hours of sleep also reported higher rates of violent delinquency, even after controlling for important factors such as impulsivity, depression, and parental supervision (Clinkinbeard et al. 2011). Interestingly, Peach and Gaultney (2013) found shorter sleep duration and delayed bedtime to be associated with delinquency in adolescence but not in young adulthood. Perhaps because of this change in associations across development, studies examining whether sleep and delinquency are associated longitudinally have yielded mixed findings. In a nationally representative sample, Catrett and Gaultney (2009) found sleep problems to be associated with delinquency concurrently but not longitudinally. In a study of young adolescents, Mrug et al. (2012) found sleep-wake cycle regularity to be correlated with delinquency 16 months later, although this association was no longer significant in analyses controlling for demographic characteristics and initial levels of delinquency and peer deviance. In contrast, Meijer et al. (2010) found sleep quality and time in bed to be associated with self-reported aggression, and the combination of poor sleep quality and shorter time in bed contributed to increases in boys' aggressive behavior over time. In a rare test of reverse associations, the authors also found delinquency and aggression to be associated with time in bed and aggression (but not delinquency) to be associated with sleep quality (Meijer et al. 2010). Of note, however, all of these studies relied on parent- or self-report of sleep functioning and youth-report of delinquency, making multi-method studies that include objective measures of sleep and official arrest records of clear necessity.

There is also a growing body of research documenting an established association between sleep and substance use in adolescence, although, again, exceptions have been reported (Bootzin and Stevens 2005). In a nationally representative sample of over 12,000 adolescents in the US, teens obtaining fewer than $8 \mathrm{~h}$ of sleep per night reported more cigarette, marijuana, and alcohol use than teens obtaining 8 or more hours of sleep each night (McKnightEily et al. 2011). Studies show that greater evening preference is associated with greater cigarette, alcohol, and marijuana use (Negriff et al. 2011; Pieters et al. 2010). In addition, Negriff et al. (2011) found an interaction between pubertal timing and morningness/eveningness in relation to cigarette use in a sample of adolescent girls, with evening preference associated with more cigarette use among girls with early or on-time pubertal timing but not among girls with late pubertal timing. Wong et al. (2009) found childhood sleep problems to longitudinally predict the onset of marijuana and cigarette use in adolescence for boys but not for girls, whereas childhood sleep problems predicted the onset of alcohol use for both boys and girls. In addition, sleep patterns characterized by inconsistency between weeknight and weekend nights (i.e., weekend delay) appear to be especially associated with increased substance use (Pasch et al. 2010) and risk-taking (O'Brien and Mindell 2005) in adolescence.

Longitudinal research indicates that sleep functioning and substance use are reciprocally related (Pasch et al. 2012), although exceptions have been reported (Shanahan et al. 2014). In addition, it is unclear if the association between sleep problems and adolescent substance use is at least partly attributable to the presence of internalizing and externalizing mental health problems (Johnson and Breslau 2001) or if the link between sleep problems and teen substance use is independent of co-occurring psychopathology (Pieters et al. 2010). Together, these findings underscore the importance of considering possible moderators (e.g., sex, biological factors) of associations, measuring sleep as a multi-faceted construct, considering important psychiatric symptoms that often co-occur with substance use, and utilizing longitudinal designs to evaluate possible bi-directional associations. In particular, since adolescent problem behaviors are often transitory in nature (Steinberg and Morris 2001) it is important to determine the degree to which sleep problems are associated with transient as well as persistent delinquent, antisocial, and substance use behaviors.

Toward an Integrated Model of Sleep and Mental Health As noted above, it is likely that sleep and mental health functioning are connected in complex ways across development, with adolescence being a critical developmental period for such interactions given the increase of both sleep problems and mental health difficulties. The developmental psychopathology tenets of equifinality and multifinality (Cicchetti and Rogosch 1996) are relevant here since it is likely that multiple, complex pathways exist. For instance, it appears that sleep problems do not confer risk for a specific mental health outcome (or select set of outcomes) but instead places youth at risk for a range of mental health difficulties (i.e., multifinality). That is, several of the studies summarized above show that sleep problems predict both externalizing and internalizing problems in adolescence (Gregory and O'Connor 2002; Gregory et al. 2008; Shanahan et al. 2014; Wong et al. 2009). Recently, Kelly and El-Sheikh (2014) used crosslagged modeling to examine the reciprocal relations among 
sleep functioning (using both actigraphy and self-report ratings) and psychopathology symptoms over a 5-year period that included the transition into adolescence. Poorer sleep functioning longitudinally predicted increases in children's anxiety, depression, and externalizing symptoms, with evidence suggesting a stronger link as youth transitioned into adolescence (from age 10 to age 13) in comparison to late childhood (age 8 to age 10). Moreover, the authors found modest support for externalizing, anxiety, and depression symptoms to predict subsequent sleep functioning, pointing to possible reciprocal, cascading processes. This is an excellent example of a multi-method, longitudinal design optimally suited to shed light on developmental processes across critical transition periods. As research continues to advance in this area, it will be crucial to also examine potential mediators (e.g., Danielsson et al. 2013) and moderators (e.g., Lemola et al. 2012) in an integrated framework that can further advance our understanding of developmental mechanisms as well as factors that may exacerbate or buffer the effects of poor sleep or confer unique risk for specific psychopathologies.

\section{Academic Factors}

Reviews of the literature clearly document that sleep problems negatively impact academic functioning (e.g., Shochat et al. 2014; Wolfson and Carskadon 2003). Importantly, the negative relation between sleep problems and academic functioning has been confirmed using both naturalistic and experimental studies (Astill et al. 2012). For example, in an experimental sleep restriction study, Fallone et al. (2005) found that restricted sleep resulted in significantly higher teacher ratings of academic problems. In another experimental study, Beebe et al. (2010) found that sleep restriction $(6.5 \mathrm{~h}$ in bed) resulted in significantly lower quiz scores in a simulated classroom environment in comparison to a healthy sleep condition (10 h in bed). In terms of naturalistic studies, Gillen-O'Neel et al. (2013) recently published data on a sample of 535 high school students who completed sleep diaries. Students who sacrificed sleep to study were more likely to have difficulties with classwork and test performance the following day (i.e., the impact was immediate). In another study of adolescents (ages 13-19), Wolfson and Carskadon (1998) found that students with a grade point average (GPA) of C's or below slept an average of $3 \mathrm{~h}$ less per night in comparison to adolescents with GPAs equivalent to B's and higher. In pointing to potential benefits of optimal sleep for youth's academics, adolescents with better sleep functioning have greater school competence in comparison to adolescents with poorer sleep functioning (Storfer-Isser et al. 2013).
Additional research points to certain adolescents being at risk for academic impairment in relation to sleep functioning. Specifically, youth with a later circadian phase preference or a weekend bedtime delay (i.e., going to bed later on weekend vs. school nights) may be more likely to experience academic impairments. O'Brien and Mindell (2005) found that adolescents with a low weekend delay (i.e., the difference between self-reported weekend-night bedtime and school-night bedtime being less than or equal to $1 \mathrm{~h}$ ) reported obtaining significantly higher grades than adolescents with a high weekend delay (i.e., the difference between weekend-night and school-night bedtime being equal to or greater than $2 \mathrm{~h}$ ). For instance, whereas $78 \%$ of youth with a low weekend bedtime delay reported getting grades of mostly A's or A's/B's, only $52 \%$ of youth with a high weekend bedtime delay reported getting mostly A or A/B grades (O'Brien and Mindell 2005). More recently, Short et al. (2013) also found a greater eveningness preference to be associated with lower grades, and the authors also extended this line of research by showing the association between eveningness preference and grades to be largely mediated by depressive symptoms. In addition, although daytime sleepiness was not associated with selfreported GPA in Short and colleagues' (Short et al. 2013) study, it is not surprising that having an evening chronotype is associated with greater daytime sleepiness (e.g., Russo et al. 2007); other studies have found daytime sleepiness to be associated with poorer academic functioning (e.g., James et al. 2011; see Dewald et al. 2010, for a review).

An important caveat to these findings is that most of the research on sleep and academic functioning completed to date has been cross-sectional in nature. In fact, the Shochat et al. (2014) review concluded that "there is a significant gap in longitudinal data examining the link between insufficient or inadequate sleep and academic functioning and performance with only three prospective investigations" (p. 80). Similarly, a recent meta-analysis focused specifically on school outcomes found that sleep quality, sleep duration, and daytime sleepiness each had a significant, negative impact on school performance, and that the strongest association was between daytime sleepiness and school outcomes (Dewald et al. 2010). Again, the authors noted that the majority of studies in the meta-analysis were cross-sectional, making longitudinal research a clear necessity since cross-sectional research does not allow the impact of sleep on the developmental trajectory of academic functioning to be evaluated and does not allow potential bidirectional associations to be tested.

In particular, there is a dearth of studies examining how poor academic functioning impacts subsequent sleep. For example, teens who find themselves underperforming academically may try to "catch up" for missed 
assignments and low test grades by staying up late to study, in turn affecting classroom learning and behavior. Other mechanisms may also shed light on how poor academic performance contributes to subsequent sleep difficulties. For example, poor school performance (and associated detachment from school) is associated with increased family/parent-child conflict (Brkovic et al. 2014; Dotterer et al. 2008), increased involvement with a negative peer group (Dishion et al. 2010; Reinke et al. 2008), and substance use (Bryant et al. 2003; Bryant and Zimmerman 2002). As described above, each of these factors may in turn contribute to sleep problems, underscoring the importance of longitudinal studies that can consider both the complex interplay of academic and sleep functioning and also test for developmental cascades and mediating processes.

\section{Contextual Factors}

A century ago, Terman and Hocking (1913) published a series of articles in the Journal of Educational Psychology on the effects of sleep on child and adolescent adjustment. After wrestling with what should be considered optimal sleep duration among youth, they concluded that "the wisest course in all probability is for us to make the conditions such that the child will spontaneously sleep as many hours per day as he wants to sleep, while avoiding all conditions which would tend either to abbreviate or unduly prolong the sleep beyond this standard" (p. 208). Although the conditions a century ago were hardly such that youth could spontaneously sleep for as long as desired, these words seem even more striking against the backdrop of the twenty-first century when, at least for many youth, the phrase 24/7 seems apropos, as adolescents juggle increasing school and homework demands, extracurricular activities and part-time employment, and a barrage of technological outlets and influences. We now turn our attention to how these contextual factors inform what we know about sleep in adolescence.

\section{Electronic Media Use}

Almost all adolescents (97\%) in the US have at least one electronic device in their bedrooms, with older teens having more electronic devices in their bedrooms than younger teens (National Sleep Foundation 2006). In addition, $62 \%$ of adolescents report using a mobile telephone (either calls or text messages) after "lights out" (Van den Bulck 2007). There is converging evidence showing media use to be negatively associated with teens' sleep functioning, including shorter sleep duration and delayed sleep onset in particular (see Bartel et al. 2014; Hale and Guan 2014, for reviews). In a cross-sectional study of 738 young adolescents (ages 11-13) in the United Kingdom, technology use was associated with shorter sleep duration and difficulty falling asleep (Arora et al. 2014). Similarly, television and computer/Internet use was associated with poorer sleep in an epidemiological study of 1,221 adolescents in South China (Zhou et al. 2012). In the US, the National Sleep Foundation's 2006 Sleep in America poll found that teens with four or more electronic devices in their bedrooms obtained less sleep than other adolescents (National Sleep Foundation 2006). Israeli adolescents with a television in their room also report later bedtimes, longer sleep latency, and overall reduced sleep duration in comparison to their peers without a television in their bedroom (Shochat et al. 2010). There is some evidence to suggest that time spent watching television may be more strongly associated with insufficient sleep for adolescent males than adolescent females (McKnight-Eily et al. 2011). Interestingly, findings by Calamaro et al. (2009) suggest that technology multitasking-engaging in a several technological activities simultaneously-is an important aspect of teen media use when considering sleep functioning. Among adolescents aged 12-18 years, having a television in the bedroom was not correlated with sleep duration but multitasking was associated with poorer self-reported sleep functioning including shorter sleep duration, greater difficulty falling asleep on weeknights, and an increased likelihood of falling asleep during school (Calamaro et al. 2009). Although these studies suggest a link between electronic media use and adolescent sleep, the cross-sectional design of these studies makes it impossible to tease apart whether technology use contributes to sleep onset difficulties and delayed bedtime or whether teens who have a hard time falling asleep turn to electronics as a way to cope with their sleep onset difficulties. For instance, $46 \%$ of high school students in the US report watching television to help them fall asleep (Noland et al. 2009). Eggermont and Van den Bulck (2006) similarly found that adolescents frequently report using media to help them fall asleep (e.g., $36.7 \%$ reported watching television and $60.2 \%$ reported listening to music to help them fall asleep), which in turn is associated with delayed bedtime, decreased sleep duration, and daytime tiredness.

Longitudinal research also shows a link between electronic media use and sleep problems. Computer usage is longitudinally associated with shorter sleep duration and more sleep problems from age 12 to age 15 years (Maume 2013). In addition, Johnson et al. (2004) found that adolescents who watched 3 or more hours of television per day were at much higher risk than their peers of experiencing sleep problems by early adulthood. Further, adolescents who reduced their television watching from $1 \mathrm{~h}$ or longer to less than $1 \mathrm{~h}$ per day experienced a notable reduction in later sleep problems. Among Japanese adolescents, mobile 
phone use after "lights out" is associated with a host of sleep indices, including shorter sleep duration, poorer sleep quality, excessive daytime sleepiness, and insomnia symptoms (Munezawa et al. 2011). In a longitudinal study of Belgian adolescents, mobile phone use for sending/ receiving calls or text messages after "lights out" was associated with at least a twofold risk of self-reporting feeling very tired 1 year later (Van den Bulck 2007). However, not all studies support the conclusion that media use increases risk for sleep problems in adolescents and emerging adults. A recent study of 942 college students found sleep problems (but not sleep duration) to predict increased time spent watching television and using social networking websites 1 year later but did not find evidence of television/social networking use predicting later sleep problems (Tavernier and Willoughby 2014). Given these unidirectional findings the authors concluded that "emerging adults appear to seek out media as a means of coping with their sleep problems" (Tavernier and Willoughby 2014).

It is clear that more research is needed to better understand the association between electronic media use and adolescent sleep. In their review of this topic, Cain and Gradisar (2010) outline several possible mechanisms that may explain the negative impact electronic media use has on youth's sleep functioning, including technology use directly displacing sleep (including delaying bedtime or by affecting other activities related to sleep hygiene such as physical activity), bright lights from electronic screens suppressing melatonin and in turn delaying youth's circadian rhythm, electromagnetic radiation from mobile phone use delaying melatonin and impacting sleep architecture, and electronic media use increasing physiological arousal. Each of these possibilities deserves more empirical scrutiny, with a particular need for studies that use longitudinal and experimental designs to examine developmental processes and mechanisms. For example, in a recent experimental study, King et al. (2013) found "prolonged" videogaming (150 min) to have a negative impact on both objective and subjective sleep indices in comparison to "regular" video-gaming (50 min), even when bedtime was kept the same in both video-gaming conditions (i.e., the prolonged video-gaming did not result in a later bedtime). Despite finding differences in sleep functioning, the investigators did not find teens in the prolonged or regular video-gaming conditions to differ in their heart rates, suggesting that physiological arousal may not be the mechanism linking technology use and sleep difficulties (King et al. 2013). However, this study consisted of only 17 participants and only included boys who had no current sleep difficulties, further underscoring the need for much more research in this area. Furthermore, studies have yet to examine how other important factors such as parent limit- setting or peer functioning (e.g., loneliness, popularity) may attenuate or exacerbate the association between teens' electronic media use and sleep functioning.

\section{Homework, Employment, and Extracurricular Activities}

Multiple studies have shown that time spent on homework is negatively associated with sleep duration. For instance, Zhou et al. (2012) found more time spent doing homework on both weekdays and weekends to be significantly associated with poorer sleep in Chinese adolescents. Time spent studying each night is also associated with less daily sleep, and a greater difference between sleep obtained on school nights versus non-school nights among adolescents in the US (Fuligni and Hardway 2006). Time spent on schoolwork is also associated with the persistence of shortened sleep among US adolescents (Roberts et al. 2011). Longitudinally, Maume (2013) found hours spent on homework during sixth grade (approximately age 12) to be associated with shorter sleep duration at age 15 years. These findings are perhaps not surprising given the increasing academic and homework demands that often accompany the transition to middle school, with 16-18-year olds spending anywhere from 10 to $65 \mathrm{~h}$ per week on homework (Kouzma and Kennedy 2002). Of note, among youth in the US, the association between time spent on homework and sleep duration appears to be limited to adolescents, with no such association present in childhood (Adam et al. 2007). In contrast, recent research shows time spent on homework to be associated with shorter sleep duration among schoolaged children in China (Sun et al. 2014). Indeed, adolescents in the US spend less time doing homework than adolescents in other industrialized countries (Larson 2001), suggesting that cultural factors may be important to consider when examining how time spent on various activities impacts teens' (and children's) sleep functioning. Further, time spent on homework may increase adolescents' stress and depressive symptomatology (Kouzma and Kennedy 2002; Leone and Richards 1989), which may in turn further impact sleep functioning.

In addition to time spent on homework, having a parttime job in adolescence is associated with reduced sleep duration and more sleep problems (Bachman and Schulenberg 1993; Maume 2013; Safron et al. 2001; Vinha et al. 2002). For example, a series of studies conducted with adolescents in São Paulo, Brazil showed employment to be a significant predictor of shorter sleep duration, poorer sleep quality, greater daytime sleepiness, and a greater sleep rebound (i.e., extended sleep duration) on weekends (Fischer et al. 2008; Teixeira et al. 2004a, b; 2007). In a study conducted by a different research team, weekend employment was linked to less total sleep time (due to earlier wake times), with each hour of paid work 
corresponding to a quarter-hour reduction in weekend sleep obtained (Adam et al. 2007). College students who work $20 \mathrm{~h}$ or more each week also obtain less sleep than their peers working less than $20 \mathrm{~h}$ per week (Miller et al. 2008), demonstrating the association between employment and reduced sleep to extend into late adolescence.

Amount of time spent on extracurricular activities (e.g., sports, clubs) is also associated with the persistence of shortened sleep in US adolescents (Roberts et al. 2011). In a study of 713 high school students in Greece, time spent on both school-related activities (e.g., tutoring) and extracurricular activities were each significantly associated with shorter sleep duration (Lazaratou et al. 2005). Similarly, greater time spent on extracurricular activities and employment is associated with obtaining less sleep in New Zealand adolescents, with adolescents spending 5 or more hours on extracurricular/employment activities being more likely to have a shortened sleep duration (Dorofaeff and Denny 2006). However, before concluding that extracurricular activities are indeed detrimental for adolescents' sleep functioning, it is important to note that extracurricular activities may have a protective effect. In a sample of over 100,000 Japanese adolescents, adolescents not participating in an extracurricular activity were at higher risk for experiencing insomnia in comparison to adolescents who did participate in an extracurricular activity (Kaneita et al. 2006). Clearly, more research is needed to identify the circumstances or factors that contribute to extracurricular activity use having either a protective or detrimental impact on adolescent sleep. For instance, perhaps there is a threshold at which extracurricular activities shift from being advantageous to instead being detrimental. Likewise, increased specificity is needed to determine if certain activities (e.g., sports, arts) or settings (e.g., school vs. nonschool activities) confer distinct risks or benefits for adolescent sleep. Also, if participation in extracurricular activities requires adolescents to stay up late doing homework or serves as a catalyst negative peer involvement, the beneficial effects of extracurricular activities may be reduced or negated (see Eccles et al. 2003).

Furthermore, although studies show a correlation between sleep functioning and time spent on various demands that often increase (e.g., homework) or begin (e.g., employment) in adolescence, few longitudinal or experimental studies exist that can help establish temporal ordering and causality. This is an important area for future research, as US adolescents commonly report homework (47\% of adolescents), after school sports (24\%), and having a part-time job $(21 \%)$ as factors that contribute to insufficient sleep (Noland et al. 2009). In addition, there is a need for studies to examine moderators and mediators of the relations of time spent doing homework, employed work, and extracurricular activities with sleep functioning.
For example, does caffeine use mediate the association between time spent on homework or at work and sleep? What is the trade-off of devoting time to homework versus time spent doing other activities such as watching television or physical activity? Does it matter if homework is completed immediately after school or immediately prior to bedtime? Do family or socioeconomic factors exacerbate associations in determining which youth seek out part-time employment and how much time is spent working each week? Are associations moderated by school and cultural factors that may vary in their expectations and pressures related to studying, homework, and academic achievement, thus contributing to greater overall stress and sleep difficulties? These are just a few of the questions that await empirical investigation.

\section{School Start Time}

School start time has been recognized as an important factor in understanding the sleep of adolescents (see Kirby et al. 2011; Owens and Adolescent Sleep Working Group 2014, for reviews). In fact, while this article and Special Issue were being prepared, the American Academy of Pediatrics released a policy statement recommending that middle and high schools delay the start of class to 8:30 a.m. or later (American Academy of Pediatrics 2014). A sizeable body of research finds earlier school start times to be associated with adolescents obtaining less sleep, exhibiting increased daytime sleepiness, and being more frequently tardy to school (Carrell et al. 2011; Carskadon et al. 1998; Dexter et al. 2003; Edwards 2012; Hansen et al. 2005; Owens et al. 2010; Wahlstrom et al. 2014; Wolfson et al. 2007; Zhou et al. 2012). Lufi et al. (2011) showed that middle school students showed improved attention and decreased impulsivity when school start time was delayed by $1 \mathrm{~h}$. Owens et al. (2010) also found that adolescents showed improved mood and greater motivation after a later school start time was implemented. Similarly, Wahlstrom et al. (2014) recently found in a longitudinal, multi-site study in the US, that a school start time of 8:35 a.m. or later was associated with adolescents obtaining better grades as well as performing better on state and national achievement tests. Importantly, studies indicate that later school times are associated with greater sleep duration specifically because adolescents report getting up later in the morning (i.e., bedtime is not varying as a function of school start time) (Wolfson et al. 2007).

In a landmark study on the impact of school start time in relation to adolescent sleep and developmental outcomes, Danner and Phillips (2008) examined the sleep habits of all high school students in a large school district in Kentucky before and after the school district initiated 1-h change in school start time (7:30 a.m. start time changed the 
following year to 8:30 a.m.). The average hours of nightly sleep increased in the year following the change in school start time, and the percentage of students obtaining at least $8 \mathrm{~h}$ of sleep per night increased from $35.7 \%$ to $50.0 \%$. In addition, state-collected county level automobile collision data before and after the change in school start time and showed a $16.5 \%$ drop in crash rates for adolescent drivers. In contrast, teen crash rates in the rest of the state (where school start times were unchanged) increased $7.8 \%$ over the same time period.

Studies conducted outside of the US also shed light on this issue. In Australia, where secondary schools start around 8:30 a.m., adolescents obtain an average of 47 more minutes more sleep per night than their US counterparts where secondary schools typically start around 7:45 a.m. (Short et al. 2013) and sometimes before 7:30 a.m. (Wolfson and Carskadon 2005). However, it is difficult to know the exact contribution of school start time specifically in increasing the sleep duration of Australian teens since Australian adolescents are also more likely to have a parent-set bedtime and spend less time on extracurricular commitments than adolescents in the US (Short et al. 2013). Nonetheless, the difference in school start times points to at least one of the likely contributors to Australian adolescents obtaining more sleep than adolescents in the US. In addition, a study of Croatian adolescents provides additional evidence of the effect of school schedule on youth's sleep patterns (Košćec et al. 2014). Due to a lack of school space to accommodate all students simultaneously, most schools in Croatia have students on alternating schedules whereby students attend classes in the morning for 1 week and then in the afternoon the next week. Using this naturally-occurring two-shift schedule, Košćec et al. (2014) found that all youth (regardless of chronotype) delayed their bedtimes and wake times when in the afternoon versus morning school schedule. However, youth with an evening chronotype (as opposed to a morning or intermediate chronotype) showed the greatest irregularity, obtaining almost 2 fewer hours of sleep per night when on the morning school schedule than the afternoon school schedule.

Together, these studies speak to the importance of school start times when examining-and seeking to improve-adolescent sleep. Still, there is a dire need for more research in this area. In particular, studies to date have primarily compared youth in schools with different start times or compared youth's functioning before and after a change in school start time. While clearly instrumental, the lack of experimental research in this area makes it difficult to establish definitive causal claims (however, see Carrell et al. 2011, for a compelling example supporting a causal link). Furthermore, studies have yet to consider potentially important moderators, such as pubertal status, chronotype, participation in extracurricular activities, and socioeconomics. Despite a preponderance of evidence that supports later school start times for American adolescents (American Academy of Pediatrics 2014), the systemic changes required to modify middle and high school start times are complicated by significant logistical, financial, and practical considerations (Wahlstrom 2002; Wolfson and Carskadon 2005). Further clarifying the impact of school start times on adolescents and identifying the systemic issues that impact public policy decisions regarding school start times is a topic well-suited to a range of research methodologies including qualitative and participatory action research alongside observational and experimental studies. Indeed, the issue of school start times is an excellent example of how research in adolescent sleep can be ultimately important for informing and guiding public policy.

\section{Neighborhood and Community Factors}

In addition to the school context, the broader community and neighborhood context is also important to consider when examining predictors and consequences of insufficient or inadequate sleep in adolescence. Several studies demonstrate community violence to be linked to poorer sleep in adolescence (Cooley-Quille and Lorion 1999; Lepore and Kliewer 2013). In a sample of almost 500 seventh-grade youth, community violence exposure was associated with lower GPA directly but also indirectly via sleep problems (Lepore and Kliewer 2013). Adolescents who obtain less than $8 \mathrm{~h}$ of sleep per night are concurrently more likely than their peers to report carrying a weapon to school, missing school due to feeling unsafe, being threatened or injured with a weapon at school, and being bullied at school (Hildenbrand et al. 2013). Longitudinal data also speak to the link between sleep problems and adolescents carrying or using weapons. In a large sample of inner-city African American adolescents, Umlauf et al. (2011) found traumagenic-related sleep problems (i.e., difficulty sleeping or experiencing nightmares due to bad things happening to a family member or friend) to be longitudinally associated with carrying, brandishing, and using a knife or gun, as well as endorsing aggressive and violent attitudes in response to disrespect or personal affront, even after controlling for exposure to violence and traumatic stress. In addition, seeing someone cut, stabbed, or shot, alcohol use, worry, and internalized anger were each longitudinally associated with sleep disturbance (Umlauf et al. 2011).

These findings point to the likely bidirectional associations between community violence and sleep problems. Indeed, sleep disturbance is a common sequela of community violence and other traumatic exposure, with both traumatic nightmares and general sleep disturbance 
identified as symptoms of posttraumatic stress disorder (PTSD) (American Psychiatric Association 2013; Charuvastra and Cloitre 2009). Moreover, just as sleep problems may be implicated in the developmental psychopathology of delinquency, there is increasing evidence that trauma exposure and posttraumatic stress symptoms are also associated with juvenile delinquency (Becker and Kerig 2011; Moore et al. 2013). Multiple mechanisms are likely implicated in the association between violence exposure (either in the home or in the community) and adolescent delinquency (Kerig and Becker 2010, 2015), but studies have yet to separate out sleep disturbances from other symptoms of PTSD when examining the link between trauma/PTSD and delinquency or other antisocial behaviors. Given the findings summarized above linking sleep to carrying/using a weapon (Hildenbrand et al. 2013; Umlauf et al. 2011), as well as other studies showing short sleep duration to be associated with violence towards others, truancy, and a criminal record for theft (Yen et al. 2010), it would behoove researchers to consider the specific role of sleep problems as one possible mechanism linking trauma and violence exposure to delinquency and other externalizing behaviors. Indeed, there is preliminary cross-sectional evidence suggesting that sleep problems may account for the link between community violence and delinquency in at-risk Latino adolescents (Rubens et al. 2014). Longitudinal studies, as well as studies that simultaneously consider multiple mediators, are needed to further clarify and extend these findings.

\section{Cultural Factors}

In addition to the school, neighborhood, and community factors discussed above, it is likewise important to consider the macrosystem of the broader cultural context when seeking to develop an integrated model of sleep in adolescence. For example, afternoon napping is common in some cultural contexts (e.g., Italy, Greece) and may help adolescents in those cultures obtain more sleep over a 24-h period (e.g., Lazaratou et al. 2005; Manni et al. 1997). Since the beneficial or detrimental effects of napping on adolescents' daytime functioning and nighttime sleep remains unclear (Fukuda and Ishihara 2002; Lemos et al. 2014), both cross-cultural and within-cultural studies would be informative by comparing nappers to non-nappers from the same cultural context as well as from different cultural contexts. Another cultural variation in sleep pertains to cosleeping. In Egyptian families for whom cosleeping is often normative, Worthman and Brown (2007) found that sleeping arrangements were "culturally patterned" (p. 132) whereby, among other findings, increased rates of solitary nighttime sleep were associated with greater sleep problems in adolescence and young adulthood. The authors speculate that "lack of an accustomed sleeping partner removes a behavioral, psychological, and physiological entrainer that can be particularly important for adolescents" (p. 133). Further investigation is warranted to examine the nuances of these cultural systems and their implications for adolescent sleep.

Finally, sleep duration varies across continents which may be due to differing cultural norms and expectations for adolescents. In a nationally representative sample of 136,589 high school students in South Korea (ages 13-18 years), $43 \%$ reported a daily sleep duration of fewer than $6 \mathrm{~h}$ and only $7 \%$ reported obtaining 8 or more hours of sleep (Do et al. 2013). Another study of South Korean adolescents found that total sleep time decreased by approximately $3 \mathrm{~h}$ from fifth to twelfth grade, with the average school-night sleep duration being only $4.86 \mathrm{~h}$ among twelfth grade students (Yang et al. 2005). These studies are in line with a meta-analysis examining geographic differences in sleep duration among adolescents from 23 countries, which found adolescents from Asian countries to sleep 40-60 min less on school nights than adolescents from the US, who in turn sleep 20-60 min less on school nights than adolescents from Europe or Australia (Olds et al. 2010). However, the extent to which these cultural differences in sleep duration moderate associations of sleep with long-term adjustment remains unknown.

\section{Bit by Bit, Putting it Together}

In Stephen Sondheim's (Sondheim 1984) Sunday in the Park with George, the Pulitzer Prize-winning musical inspired by Georges Seurat's famous painting, the title character offers a commentary on the difficulties of creating art, singing at one point that it occurs "bit by bit, putting it together." This phrase is likewise fitting for the study of sleep in adolescence. As is clear from the proliferation of research in this area, there are undoubtedly numerous factors that influence adolescents' sleep just as there are numerous ways sleep impacts adolescents' development and adjustment. The aim of this article is to further lay the groundwork for an increasingly integrated approach to the study of sleep in adolescence, considering biological maturation alongside the unique psychosocial and contextual challenges that teens face. Certainly, this is not a new notion and much progress has already been made toward this goal. Nonetheless, considerable efforts and resources will still be needed to further advance an integrated understanding of sleep in adolescence, and as with most research endeavors it will almost certainly occur bit by bit.

Indeed, although a broad swath of research findings were summarized above, the review was not intended to be comprehensive in either its depth or scope. Rather, we 
sought to illustrate some of the causes and consequences of adolescent sleep difficulties as well as to highlight some of the most recent findings in this area. Nonetheless, in order to limit the scope of this article we were unable to discuss sleep disorder diagnoses or several important research areas that are connected to adolescent sleep, including obesity (Guidolin and Gradisar 2012; Hart et al. 2011), caffeine use (Bartel et al. 2014; Roehrs and Roth 2008), the hypothalamic-pituitary-adrenal (HPA) axis and associated cortisol awakening response (CAR) (Elder et al. 2014), cognition and memory (Beebe 2011; Kopasz et al. 2010), and potential moderating factors such as sex and race/ ethnicity (Gregory and Sadeh 2012; Olds et al. 2010). These too are clearly important areas for ongoing empirical attention and several articles in this Special Issue focus on these topics.

Given the complexity inherent to the model outlined above, we now turn to ADHD as a specific topic that could certainly be informed by such a model. By providing an exemplar of how the proposed model may be applied to a specific population, we provide concrete examples of how the model can inform research questions that will advance the knowledge "bit by bit" while at the same time hoping to encourage investigators to consider how the proposed model may relate to their own areas of interest.

\section{Sleep and ADHD}

Before launching into how the study of sleep and ADHD may benefit from the biopsychosocial and contextual model described herein, it is important to note that inadequate or insufficient sleep is associated with greater attentional problems in typically developing youth (and for some youth, overactivity as well). The interest in the effects of sleep on attention-and possible overlap with ADHD-is longstanding. Almost 20 years ago, Dahl (1996) observed that "numerous clinicians and clinical investigators have commented on how some sleep deprived children can manifest cognitive and behavioral changes that mimic attention deficit hyperactivity disorder (ADHD)" (p. 44). Interest in this possible overlap has hardly abated over the last two decades, with a recent professional article referring to the correlation between children's bedtime practices/routines and ADHD medication use as "faux-ADHD" (Pressman and Imber 2011) and a New York Times article titled 'Diagnosing the Wrong Deficit' asking, "What if a substantial portion of [ADHD] cases are really sleep disorders in disguise?" (Thakkar 2013).

Many observational and experimental studies of typically developing children have documented a significant association between poorer sleep functioning and higher levels of inattention (e.g., Aronen et al. 2000; Becker 2014; Fallone et al. 2005; Paavonen et al. 2009). Although not as much work has been completed with adolescent samples, findings seem to converge with studies conducted in children. For example, in a cross-sectional study of 384 adolescents, $84 \%$ reported that obtaining inadequate sleep (defined as fewer than $9 \mathrm{~h}$ on most school nights) contributed to having more difficulties paying attention (Noland et al. 2009). In a prospective, population-based cohort study of youth in Australia, sleep problems in toddlerhood were strongly associated with inattention at age 14 (O'Callaghan et al. 2010). Similarly, in an 11-year longitudinal study of 490 adoptive and nonadoptive (biological) youth in the US, sleep problems in toddlerhood predicted attention problems in adolescence, even after controlling for attention problems in toddlerhood (Gregory and O'Connor 2002). Interestingly, attention problems in toddlerhood also predicted sleep problems in adolescence after controlling for toddlerhood sleep problems (Gregory and O'Connor 2002), suggesting a bidirectional association between sleep problems and inattention in youth.

Experimental studies provide further evidence that poor sleep has a negative impact on adolescents' attention. For example, in a sample of children and adolescents (ages 8-15 years), sleep restriction ( $4 \mathrm{~h}$ of sleep during an overnight laboratory visit) was associated with greater inattentive behaviors but not greater hyperactivity-impulsivity, although sleep restriction did not affect laboratory tests assessing sustained attention or response inhibition (Fallone et al. 2001). More conclusively, Beebe et al. (2008) implemented an at-home experimental sleep restriction protocol in 19 typically developing adolescents (ages 13-16 years). The sleep protocol consisted of three conditions that each lasted 1 week: baseline, shortened sleep (weekday nights limited to $6.5 \mathrm{~h}$ in bed), and extended sleep (weekday nights extended to $10 \mathrm{~h}$ in bed). Among other findings, adolescents displayed more parentand self-reported problems with attention during the shortened sleep week in comparison to the extended sleep week. These experimental findings are important for demonstrating a causal link between inadequate sleep and inattention. Taken together, these studies show inadequate or poor quality sleep to be associated with attentional difficulties in typically developing youth. However, these studies do not address mechanisms, predictors, or consequences of sleep problems in youth diagnosed with ADHD.

The linkages between sleep and DSM-defined ADHD are complex and are thoroughly considered in several reviews (Gruber 2009; Kirov and Brand 2014; Stein et al. 2012; Yoon et al. 2012). What is clear is that sleep problems are considerably more common in individuals diagnosed with ADHD in comparison to the general population, with approximately $30 \%$ of children and $60 \%$ of adults 
with ADHD exhibiting significant sleep problems (Yoon et al. 2012). A diagnosis of ADHD is associated with a wide-range of sleep problems but is most consistently linked with inadequate sleep duration, poor sleep quality, and daytime sleepiness (Cortese et al. 2009; Gruber 2009). The association between ADHD and sleep problems has been documented for several decades, with restless sleep even included as a symptom of Attention Deficit Disorder in the Third Edition of the DSM (American Psychiatric Association 1980). Importantly, although stimulant medication use may impact sleep onset and sleep duration (Kirov and Brand 2014), some studies find no differences in sleep functioning among medicated versus non-medicated youth with ADHD (e.g., Becker et al. 2014; Moreau et al. 2014) and other studies show that youth with ADHD who are not taking stimulant medications continue to have significantly higher rates of sleep problems in comparison to their peers (Cohen-Zion and Ancoli-Israel 2004; Stein et al. 2012). Accordingly, the high prevalence of sleep problems in youth with ADHD is not solely an artifact of stimulant medication use.

Remarkably little is known about how sleep problems contribute to the functioning of adolescents with ADHD or why prevalence rates are so high. In fact, the most recent meta-analysis examining the sleep functioning of youth with ADHD in comparison to typically developing youth identified only three studies with participants above age 14 years, with all three of these studies using a cross-sectional design (Cortese et al. 2009). In identifying the need to spur research in this area, a multidisciplinary group of experts in sleep and ADHD was recently formed to develop a consensus working group report to guide future research on sleep and ADHD (Owens et al. 2013). This group developed a list of key future research questions which included: (1) How might an enhanced understanding of the interrelationships among systems help elucidate neural mechanisms linking attention, sleep-wake regulation, and behavior?; (2) What is the relative impact of naturalistic sleep curtailment commonly experienced by middle and high school students on the functioning of children with ADHD compared to typically developing children?; and (3) Are children with ADHD more vulnerable to the effects of sleep loss? (see Owens et al. 2013). We posit that a biopsychosocial and contextual framework is well-positioned to help answer these questions and advance what is currently known about the interrelations of sleep and ADHD in adolescence.

Applying a Biopsychosocial and Contextual Model to the Study of Sleep and ADHD

In addition to biologically-based structures and networks described below that can shed light on the associations between inadequate sleep and ADHD (as well as attention problems more broadly), adolescents with ADHD experience a host of functional impairments that often extend to multiple domains of functioning. For example, compared to their peers, adolescents with ADHD experience higher rates of family conflict (Deault 2010), peer problems (Gardner and Gerdes 2013), academic failure (DuPaul and Langberg 2014), comorbid mental health problems (Larson et al. 2011), substance use (Lee et al. 2011), and driving citations/crashes (Barkley et al. 1996). As discussed above, sleep is also related to each of these functioning domains. Given these wide-ranging impairments, in addition to the possibly overlapping neurophysiological processes, adolescents with ADHD are an ideal population in which to study the causes, correlates, and consequences of sleep problems in adolescence. Further, studies including adolescents with and without ADHD (as well as adolescents with subclinical ADHD symptoms; see Cicchetti and Rogosch 2002; Sibley et al. 2012) are especially wellsuited for examining psychosocial and contextual factors that intersect with adolescents' sleep functioning. A few of these factors are discussed next in order to demonstrate how considering psychosocial and contextual factors can advance our understanding of sleep in adolescents with ADHD, a population of youth at heightened risk for experiencing significant sleep difficulties.

\section{Example Biological Factors}

Studies comparing objective sleep indices between youth with and without ADHD have yielded mixed findings, but there is converging evidence that the sleep problems and patterns of youth diagnosed with ADHD do appear to be different than their peers (Cortese et al. 2009; Kirov and Brand 2014). For example, although no differences were found in overall sleep architecture, a meta-analysis of studies using objective measures of sleep found that, in comparison to typically developing youth, children with ADHD had longer sleep onset latency [as measured with actigraphy but not with polysomnography (PSG)], lower sleep efficiency (based on PSG but not actigraphy), shorter true sleep time (based on actigraphy), a greater number of sleep stages/shifts per hour (based on PSG), shorter time to fall asleep during the Multiple Sleep Latency Test (MLST; indicating greater daytime sleepiness), and a higher apnea-hypoapnea index (Cortese et al. 2009). In addition, the lack of consistent findings pertaining to sleep architecture may be due to youth with ADHD differing from typically developing children in the developmental trajectory of rapid eye movement (REM) sleep (so-called "active sleep"). Specifically, prior to age 10, youth with ADHD display less REM sleep than their peers, but this trend reverses around the transition to 
middle school, as adolescents with ADHD display significantly more REM sleep than age-matched controls (Kirov and Brand 2014). Although the reasons for and implications of this developmental difference is unknown, Kirov and Brand (2014) suggest that "a pathological maturation of REM sleep may signify sleep pattern in ADHD” (p. 291) and have implications for learning, memory, and emotion regulation. Studies that longitudinally examine these sleep parameters in typically developing adolescents as well as adolescents with clinical and subclinical ADHD would be optimal for understanding how sleep functioning fits within the developmental psychopathology of ADHD.

Relatedly, the same brain regions that modulate sleep are implicated in prominent theories of ADHD. As summarized by Owens et al. (2013), "the cortical and brain stem regions involved in the regulation of arousal and attention and the most sensitive to sleep deprivation are also among the major sites implicated in the pathophysiology of ADHD" (p. 555). In the frontal lobes, the PFC shows the greatest change as individuals transition from waking to sleeping states (Braun et al. 1997) and is thus particularly vulnerable to sleep loss (Curcio et al. 2006; Muzur et al. 2002). As noted above, the PFC is also implicated in risk taking behaviors (Telzer et al. 2013). The PFC (as part of the frontoparietal control network) also mediates executive functions (EF) that are responsible for self-regulation and purposeful, goal-directed behavior (Banich 2009; Pennington and Ozonoff 1996). Indeed, sleep problems among youth are associated with increased EF deficits across both observational (Anderson et al. 2009; Moreau et al. 2013) and laboratory (Gruber et al. 2011; Sadeh et al. 2003) studies. In adolescents specifically, Anderson et al. (2009) found that typically developing adolescents classified with excessive daytime sleepiness had poorer parent-reported EF in comparison to adolescents without excessive sleepiness, with sleepiness most strongly associated with poorer functioning in the metacognitive facets of $\mathrm{EF}$ such as planning/organization, monitoring, working memory, and initiation. Although not universal, many youth with ADHD experience EF deficits (Willcutt et al. 2005). Moreover, the metacognitive EF domains associated with daytime sleepiness in the Anderson et al. (2009) study of typically developing youth are the same EF domains most strongly linked to poorer academic functioning among adolescents with ADHD (Langberg et al. 2013). Hence, it is possible that the association between sleep problems and academic functioning is mediated by metacognitive EF deficits. The added presence of sleep problems may make adolescents with ADHD particularly susceptible to greater EF deficits, in turn leaving these youth at particular risk for academic impairments.
In addition, the default mode network-consisting of areas of the brain that are more active during rest than during attention-demanding tasks-is implicated in a range of mental health disorders (Broyd et al. 2009; WhitfieldGabrieli and Ford 2012), including recent theories of ADHD (Sonuga-Barke and Castellanos 2007). It is hypothesized that the attentional lapses characteristic of ADHD (e.g., reaction time variability; Tamm et al. 2012) may be attributable to inadequate or decreased suppression of the default mode network during cognitive tasks (Broyd et al. 2009; Castellanos et al. 2005). Of note, altered coherence in the default mode network has been found in individuals with ADHD (Castellanos et al. 2008; Fair et al. 2010) and in sleep deprivation studies with non-ADHD youth (De Havas et al. 2012; Gujar et al. 2010), although we are unaware of any study that has integrated these two research areas. Does altered coherence in the default mode network contribute to the increased rates of sleep problems in samples of youth with ADHD? Conversely, does inadequate sleep impact the default mode network and lead in turn to attention problems? Given the prevalence of sleep problems in adolescence, studies during this developmental period that compare the default networks of adolescents with and without ADHD under conditions of optimal sleep, typical sleep, and sleep deprivation would be tremendously informative.

\section{Example Psychosocial Factors}

Family factors may uniquely contribute to the sleep problems of adolescents with ADHD. In particular, parents of adolescents with ADHD describe their family environments as being less organized and structured and having significantly greater family conflict in comparison to parents of adolescents without ADHD (Deault 2010; Schroeder and Kelley 2009). Moreover, parents of adolescents with ADHD are less likely to provide consistent and clear structure surrounding house-rules and routines such as bedtime (Deault 2010), and as reviewed above, adolescents without consistent parent-set bedtimes obtain less sleep and have greater daytime sleepiness than adolescents with parent-set bedtimes (National Sleep Foundation 2006; Noble et al. 2012; Short et al. 2011). Further, parenting behaviors such as monitoring and rejection/hostility are associated with delinquency (Hoeve et al. 2009), affiliation with deviant peers (Claes et al. 2005; Galambos et al. 2003), and substance use (Burke et al. 2001; Dishion et al. 2004; Marshal et al. 2003), which in turn is likely to impact sleep functioning. There is recent evidence to suggest that parents' knowledge of their adolescent's activities and whereabouts is associated with less delinquency and substance use for all teens but may be especially critical for teens with ADHD (Walther et al. 2012). It is unknown, 
however, the degree to which family factors contribute to the sleep problems commonly experienced by adolescents with ADHD or whether such associations are moderated or mediated by problem behaviors or a negative peer group.

A second psychosocial factor that likely contributes to the sleep problems of adolescents with ADHD is academic functioning. Academic impairments are pervasive in adolescents with ADHD (DuPaul and Langberg 2014). Although sleep problems are clearly associated with academic problems in community-based samples (Shochat et al. 2014), we are aware of only two studies that have examined sleep and academics in adolescents diagnosed with ADHD. First, Langberg et al. (2013) found selfreported daytime sleepiness to be significantly associated with parent- and teacher-rated academic functioning such as homework problems, overall academic impairment, and academic competence. However, this study was crosssectional and evaluated only one aspect of sleep functioning. In addition, the sample was an early adolescent sample $\left(M_{\text {age }}=11.9\right)$ and studies following the developmental trajectory of sleep problems suggest that difficulties with daytime sleepiness continue to increase in severity during and after the transition to high school (Fredriksen et al. 2004; Shinkoda et al. 2000). Accordingly, it is likely that daytime sleepiness would have an even more detrimental impact on academic functioning in an older sample of adolescents with ADHD. In line with this possibility, Langberg et al. (2014a) conducted the only longitudinal study published to date focused on the relation between daytime sleepiness and academic outcomes in adolescents with ADHD. In a sample of 62 college students $\left(M_{\text {age }}=19.5\right)$ rigorously diagnosed with ADHD, selfreport of daytime sleepiness longitudinally predicted school problems and overall functional impairment as well as the number of $\mathrm{D}$ and $\mathrm{F}$ grades received. Additional analyses conducted with this college sample found evidence for bidirectional associations whereby school maladjustment longitudinally predicted daytime sleepiness, and of note, this association was mediated by internalizing symptoms and low locus of control specifically (Langberg et al. 2014b). Of note, the series of studies conducted by Langberg and colleagues included only adolescents with ADHD, making it impossible to evaluate whether interrelations between sleep and functioning differed for adolescents with and without ADHD. Nevertheless, the results of these studies provide support for a potential longitudinal relation between sleep and academic functioning in adolescents with ADHD, and it is possible that high rates of academic problems in youth with ADHD contributes to the pervasive academic impairments experienced by this population, with bidirectional associations between sleep and academics also likely.
A third important psychosocial factor to consider when examining sleep in adolescents with ADHD is psychiatric comorbidity, as co-occurring externalizing and internalizing mental health problems are highly prevalent among adolescents with ADHD (Smalley et al. 2007). Several recent studies (Accardo et al. 2012; Hansen et al. 2011, 2014) have found that youth with comorbid ADHD and internalizing problems (i.e., anxiety, depression) have more sleep problems than youth with ADHD alone, including greater daytime sleepiness in addition to shorter sleep duration and more frequent night awakenings. For example, Moreau et al. (2014) found that youth with comorbid ADHD and anxiety had the longest sleep onset delay, shortest sleep duration, and greatest daytime sleepiness in comparison to typically developing youth or youth with ADHD alone. In addition, Sung et al. (2008) found comorbid conduct problems to be a strong predictor of sleep problems in youth with ADHD. Interestingly, Lycett et al. (2014) recently found that it was not the presence of either an internalizing or externalizing comorbidity but rather the presence of both an internalizing and externalizing comorbidity that was associated with increased sleep problems among children with ADHD. In prospective analyses conducted with the same sample, Lycett et al. (2014) also found that the co-occurrence of both internalizing and externalizing comorbidities (as opposed to internalizing or externalizing comorbidity alone) predicted not only transient sleep problems but also the persistence of sleep problems over a 1-year period. Taken together, these findings point to comorbidity as an important risk factor for increased sleep problems among youth with ADHD and there is recent evidence to suggest sleep problems may likewise contribute to comorbid symptoms in youth with ADHD. Specifically, in a sample of 81 young adolescents (ages 10-14 years) diagnosed with ADHD, sleep problems predicted externalizing behaviors and depressive symptoms (but not anxiety symptoms) 1 year later, even after controlling for initial levels of comorbid symptoms (Becker et al. 2014). Taken together, studies examining sleep and comorbidity in ADHD samples point to potential bidirectional associations. However, all of these studies were conducted in school-aged children/young adolescents (Becker et al. 2014; Hansen et al. 2011, 2014; Lycett et al. 2014a, b; Moreau et al. 2014) or in samples with a wide age range (ages 5/6-18) (Accardo et al. 2012; Sung et al. 2008), leaving it unclear how sleep and mental health are interconnected in youth with ADHD during middle and older adolescence when rates of certain mental health problems such as conduct disorder (Merikangas et al. 2010), substance use (Molina and Pelham 2003), and depression/ suicidal ideation (Hinshaw et al. 2012) are higher. Further, aside from the recent 1-year longitudinal studies by Becker et al. (2014) and Lycett et al. (2014a), all of the studies 
completed to date have been cross-sectional, leaving it unclear if comorbidities predict increases in sleep problems (and vice versa) over longer developmental periods or whether comorbid mental health symptoms differentially impact the sleep of adolescents with and without ADHD.

\section{Example Contextual Factor}

Homework difficulties are one contextual factor especially relevant to adolescents with ADHD. A significantly higher percentage of youth with ADHD experience homework difficulties in comparison to typically developing youth (74 and $28 \%$, respectively; Coghill et al. 2008). Adolescents with ADHD are more likely than their peers to fail to bring home assignments, not know what was assigned, and procrastinate in completing work (Power et al. 2006). Further, when completing homework, adolescents with ADHD often have difficulty staying on-task and rush through and make careless mistakes (Power et al. 2001). Importantly, parents report that most of these difficulties are concentrated during the late afternoon and evening hours leading up to bedtime (Coghill et al. 2008). Further, homework difficulties and conflict surrounding homework and studying appears to contribute to the night-to-night variability in sleep functioning (e.g., bedtime, sleep onset delay) observed in youth with ADHD (Gruber and Sadeh 2004; Gruber et al. 2000; Hvolby et al. 2008; Moreau et al. 2014). This sleep variability may be due to "problematic nights" resulting from a combination of factors, including psychosocial factors described above (i.e., family factors, high rates of comorbid mental health conditions) in addition to homework problems such as procrastination and homework completion difficulties that negatively impact bedtime, sleep latency, and sleep quality (Moreau et al. 2014). As noted above, research in community samples has demonstrated that a single instance of staying-up late to study during the week can have a negative impact on functioning in school the next day (Gillen-O'Neel et al. 2013). Considering the frequency with which adolescents with ADHD experience significant homework problems, it seems likely that homework completion difficulties could significantly impact their sleep patterns, perhaps to a greater degree than their peers.

\section{Concluding Thoughts on the Interrelations of Sleep} and ADHD

The research and clinical relevance of the aforementioned biological, psychosocial, and contextual factors seem clear. However, it remains that these important biopsychosocial and contextual factors have yet to receive adequate empirical attention in adolescents with ADHD. Given the range of factors that may be related to sleep functioning and sleep variability in youth with ADHD, applying a biopsychosocial and contextual framework to this area of research would be instrumental in teasing apart what mechanisms exert the strongest influence in the development of sleep problems among youth with ADHD and whether distinct developmental processes link sleep problems to adverse outcomes among teens with ADHD in comparison to other teens.

In addition, we have touched on only some of the most salient aspects of sleep and ADHD that warrant further empirical investigation. Consistent with a developmental psychopathology framework (Cicchetti and Rogosch 2002), there is a need for studies that do not simply compare adolescents with and without ADHD in their sleep functioning but seek to unearth the developmental processes that lead to group differences in sleep functioning. For example, a recent study of 75 children (ages 7-11) with and without ADHD found that children with ADHD had a stronger circadian evening preference in comparison to other children (Gruber et al. 2012). Although this study was conducted with school-age children it has clear implications for examining sleep and ADHD in adolescence. A stronger eveningness preference, especially when occurring at a younger age than other youth, may put youth with ADHD at even greater risk for negative correlates of eveningness preference in adolescence including poor academic performance (Short et al. 2013), increased sensation seeking (Muro et al. 2012), and externalizing behaviors (Susman et al. 2007). These possibilities point to critical questions in need of empirical attention. For instance, does ADHD confer unique risk for sleep problems or are sleep problems part and parcel of ADHD for at least a subset of youth with ADHD and what are the roles of neurobiology and sleep architecture in teasing apart these possibilities? In addition, it is clear that sleep problems adversely affect the functioning of typically developing adolescents, so are associations in teens with ADHD qualitatively different (with unique mechanisms and moderators) or are associations simply quantitatively different? Answers to questions such as these are critical for informing models of sleep as they relate to both ADHD and typical development in adolescence.

\section{Overview of Special Issue Contributions}

We now turn to the nineteen empirical studies included in this Special Issue and briefly comment on their contributions, focusing in particular on how these studies are informed by the biopsychosocial and contextual model of sleep in adolescence proposed in this introductory article.

Three articles in this Special Issue focus on the identification of physical and physiological characteristics that 
may relate to both sleep and adjustment in adolescents and college students. First, Peach et al. (2015) examined body mass index (BMI) as a possible mediator of the association between sleep problems and hypertension risk in a sample of sixth grade students (ages 11-13 years). Interestingly, sex-specific patterns emerged: whereas school-night sleep duration, weekend night sleep duration, and daytime sleepiness were each associated with boys' BMI which was in turn associated with hypertension risk; only daytime sleepiness was associated with girls' BMI and had a significant indirect effect on hypertension risk. The study by Jarrin et al. (2015) also focuses on obesity and found sympathovagal imbalance to mediate the association between poor sleep (and later sleep timing and sleep-disordered breathing in particular) and obesity indices in a sample of 564 young adolescents (ages 10-12 years) atrisk obesity. Shifting gears to the CAR, Sladek and Doane (2015) used daily sleep diaries and actigraphy in college students to examine the interrelations of sleep, loneliness, and the HPA axis. The authors found that feeling more socially connected was associated with more time spent in bed and more time asleep for college students high in trait loneliness but associated with a longer sleep onset latency for students low in trait loneliness. In addition, for all students (regardless of trait loneliness level), increases in daily social connection were linked to an enhanced CAR the next day, providing intriguing evidence that social connection can influence college students' sleep while also promoting biological readiness for the next day's activities. These studies underscore the value and importance of including biological measures in studies examining adolescents' sleep patterns and functioning. In addition, although not focused on physical and physiological characteristics, the Tavernier and Willoughby (2015) study in this issue complements the Sladek and Doane (2015) study by examining the bidirectional associations between sleep problems and social connectedness. In a 3-year longitudinal study of 942 university students Tavernier and Willoughby (2015) found that sleep quality was prospectively associated with more positive social ties and that this association was mediated by emotion regulation. In addition, cascading processes emerged, as positive social ties contributed to more effective emotion regulation which in turn contributed to fewer sleep problems.

The next two articles both touch on an important psychosocial domain: family functioning. Two large, nationally representative samples of adolescents in Georgia $(N=6,992)$ and Switzerland $(N=5,575)$, Vazsonyi et al. (2015) tested whether sleep quality and quantity accounts for the association between parental warmth and problem behaviors (i.e., alcohol use, illegal drug use, deviant behaviors). This hypothesis was largely supported and results were remarkably consistent across the two samples, pointing to the importance of positive parenting behaviors for promoting sleep behaviors and in turn reducing risk for engaging in problematic behaviors. Using a phone diary interview methodology, Kuo et al. (2015) examined the family context (in addition to school, work, and peer contexts) in a sample of 246 Mexican-American adolescents. The authors found that more time spent working, at school, or with peers was associated with obtaining less sleep. In addition, the authors found that conflict with mothers (but not fathers) was associated with increased sleep variability whereas intimacy with parents was not associated with either sleep duration or sleep variability in this sample. The authors propose some intriguing culturally-nuanced possibilities in discussing these findings, including discussing how the role of mothers in traditional Mexican-American families might interact with sleep functioning.

The next group of articles broadly focuses on the interrelations of sleep functioning with internalizing symptoms and externalizing behaviors. Consistent with previous research, Winsler et al. (2015) examined sleep in a sample of over 27,900 students in 8th, 10th, and 12th grades and found that, on average, students report obtaining fewer than $7 \mathrm{~h}$ of sleep on weekdays, with high school students (10th and 12th graders) obtaining an hour less of sleep than middle school students (8th graders). Moreover, obtaining just $1 \mathrm{~h}$ less of weekday sleep was associated with increased odds of hopelessness, suicidal ideation, suicide attempts, and substance use. These findings are consistent with those of Pieters et al. (2015) who found that sleep problems prospectively predicted increased substance use, internalizing symptoms, and externalizing problems 1 year later in a sample of 555 adolescents (ages 11-16 years), even after controlling for baseline levels of adjustment, age, sex, and pubertal development. Of note, no evidence was found for reverse associations of substance use, internalizing symptoms, or externalizing problems predicting later sleep problems, with the exception of alcohol use predicting increased sleep difficulties 1 year later. Doane et al. (2015) also examined the bidirectional association of sleep with internalizing symptoms. In a three-wave, multi-method study using both actigraphy and self-report ratings across the transition from high school to college, subjective sleep quality predicted anxiety which in turn predicted subsequent sleep problems. In contrast, initial levels of depressive symptoms in the spring of the senior year of high school predicted increased subjective sleep problems and actigraphy-measured sleep onset latency and sleep start variability in the fall of the first year of college. In considering these results alongside the findings of Pieters et al. (2015), it is possible that a developmental progression occurs whereby sleep problems confer risk for depressive symptoms in early-to-mid adolescence 
whereas the presence of depressive symptoms in late adolescence impacts subsequent sleep.

Intriguingly, Lemola et al. (2015) found electronic media use before bed to be associated with teens' depressive symptoms, with reduced sleep duration accounting for this association. Although the cross-sectional design precludes making causal inferences, these findings nonetheless point to the importance of considering adolescent-salient contextual factors when examining the concurrent and longitudinal link between sleep and depression. The study by Yip (2015) points to ethnic/racial discrimination as another important factor for consideration, as adolescents reporting high levels of ethnic/racial discrimination (regardless of ethnic background) reported a decrease in self-esteem and an increase in depressive symptoms over a 3-year period.

Four longitudinal studies point to the role of sleep problems in understanding externalizing behaviors in adolescence. First, Lin and Yi (2015) use three waves of data from the Taiwan Youth Project to examine the concurrent and longitudinal associations of sleep problems with conduct problems. Among other findings, the investigators found poor academic performance to longitudinally mediate the association between short weekend sleep and conduct problems. Second, Thomas et al. (2015) found sleep functioning to remain relatively stable from early childhood (age 2) through adolescence (age 15). In addition, although no direct association emerged between sleep problems (at any age) and risk-taking in late adolescence (age 18), some evidence was found for working memory (a component of executive functioning) being a mechanism linking adolescent sleep problems to risk-taking. These two studies underscore the importance of both academic and cognitive factors for understanding possible developmental pathways linking sleep to adolescent behavior problems and risk-taking. Third, Meldrum et al. (2015) found the association between sleep problems and delinquency (a latent factor comprised of substance use, non-violent delinquent behaviors, and violent behaviors) to be mediated by low self-control, even after accounting for prior delinquency, neighborhood context, parenting practices, unstructured peer socialization, and depression. Fourth, using Add Health data, McGlinchey and Harvey, (2015) found a late bedtime in adolescence $\left(M_{\mathrm{age}}=16\right)$ to predict cigarette use, alcohol abuse, illicit drug use, criminal activity, and emotional distress 6 years later $\left(M_{\text {age }}=21.8\right)$, with all but one of these associations (alcohol abuse) still significant when controlling for parent-child attachment and peer delinquency. In contrast to some previous studies (e.g., Liu 2004; Winsler et al. 2015; Wong and Brower 2012), the authors did not find sleep duration in adolescence to increase risk for suicidality in young adulthood, and there is clearly a need for more longitudinal work in this area. The study by Barnes and Meldrum (2015) also points to the importance of considering genetic and environmental factors. In their study of monozygotic twin pairs in the Add Health sample, the associations of sleep duration with several outcomes including suicidal ideation, delinquency, and drug use were reduced to non-significance when genetic and shared environmental factors were accounted for in the model. Importantly, the association between sleep duration and lowered self-control and increased depressive symptoms remained significant when accounting for genetic and shared environmental factors. Although more studies are certainly needed to replicate and extend these findings (particularly given the cross-sectional design and limited measurement of sleep and outcome domains), this study offers an important reminder to researchers to not overstate findings from any single study that is unable to consider all potential confounds.

Studies by Kliewer and Lepore (2015) and Umlauf et al. (2015) draw our attention to ways in which exposure to violence can impact sleep functioning. Among 362 young adolescents (ages 11-14 years) who witnessed or experienced community violence, both victimization and witnessing violence were longitudinally correlated with sleep problems (Kliewer and Lepore 2015). However, path modeling conducted using four measurement points over an 18-month period indicated that witnessing violence (but not victimization) reported at the first time-point was associated with more social constraints in talking about violence at the second time-point which was associated at the third time-point with having more intrusive thoughts related to the violence experienced. These intrusive thoughts were associated with poorer sleep quality at the final time-point. These findings provide compelling support for the role of social-cognitive processes in understanding how violence exposure can impact sleep functioning. In another longitudinal study, Umlauf et al. (2015) extended previous work with the Mobile Youth Survey (Umlauf et al. 2011) by showing violence exposure and hopelessness to have independent and multiplicative effects on adolescent sleep trajectories, with trauma-exposed females at particular risk for subsequent sleep problems related to traumatic stress. These studies provide excellent examples of integrating the community context into models of adolescent sleep.

Finally, the study by Logan et al. (2015) examines changes in sleep habits across adolescent pain rehabilitation. Not only did sleep habits improve over the course of rehabilitation treatment (with continued improvements at a 1-to-3-month follow-up), but better sleep habits at the end of rehabilitation were correlated with lower pain intensity ratings and also predicted global and school functioning at follow-up. While this Special Issue has a theoretical focus 
on the development and consequences of sleep problems in adolescence, this study is a reminder that work in this area should ultimately be used to inform prevention and intervention efforts, as well as public policy. This is critically important and helps ensure that scientific endeavors are not merely theoretical exercises but are ultimately useful for fostering optimal development and improving the lives of children and adolescents.

\section{Conclusion}

The articles included in this Special Issue together provide an excellent example of how the study of sleep in adolescence can be grounded in developmental science and a developmental psychopathology framework. In line with the developmental focus of the Journal of Youth and Adolescence, manuscripts that were theoretically-grounded and used a longitudinal design and/or large sample size were especially well-suited for this Special Issue. Nonetheless, it is important to note that the broader examination of sleep in adolescence will continue to benefit from studies using a range of methodologies, including multiinformant perspectives, multi-method measurement of sleep functioning (including laboratory-based measures), and both clinical and nonclinical samples. Given the amount of financial and other resources necessary for executing longitudinal studies or studies using objective, laboratory-based measures such as PSG, it is difficult for any single study to be both longitudinal and multi-method and also have an adequate sample size for testing developmentally-focused hypotheses (e.g., moderation, mediation, developmental cascades). In many cases, investigators must work towards building certain strengths into their study (e.g., representative sample, longitudinal design) while acknowledging that this may in turn mean sacrifices in other areas (e.g., limited measure of sleep functioning). Ultimately, a range of studies using a multitude of methodologies are needed to inform our understanding of sleep in adolescence. Indeed, as noted above, although we have already learned much about the development, importance, and impact of sleep in adolescence, there is much that remains to be understood. Studies using diverse methodologies and samples, including the studies included in this Special Issue, will ensure that our understanding of sleep in adolescence continues to advance "bit by bit."

Conflict of interest The authors report no biomedical financial interests or potential conflicts of interest.

Author contributions S.P.B., J.M.L., and K.C.B. each participated in the development and writing of the manuscript. All authors read and approved the final manuscript.

\section{References}

Accardo, J. A., Marcus, C. L., Leonard, M. B., Shults, J., Meltzer, L. J., \& Elia, J. (2012). Associations between psychiatric comorbidities and sleep disturbances in children with attention-deficit/ hyperactivity disorder. Journal of Developmental and Behavioral Pediatrics, 33, 97-105. doi:10.1097/DBP. 0b013e31823f6853.

Adam, E. K., Snell, E. K., \& Pendry, P. (2007). Sleep timing and quantity in ecological and family context: A nationally representative time-diary study. Journal of Family Psychology, 21, 4-19. doi:10.1037/0893-3200.21.1.4.

Adams, G. C., Stoops, M. A., \& Skomro, R. P. (2014). Sleep tight: Exploring the relationship between sleep and attachment style across the life span. Sleep Medicine Reviews, 18, 495-507. doi:10.1016/j.smrv.2014.03.002.

American Academy of Pediatrics. (2014). School start times for adolescents. Pediatrics, 134, 642-649. doi:10.1542/peds.20141697.

American Psychiatric Association. (1980). Diagnostic and statistical manual of mental disorders, Third Edition (3rd ed.). Washington, DC: American Psychiatric Association.

American Psychiatric Association. (2013). Diagnostic and statistical manual of mental disorders: Fifth Edition (5th ed.). Washington, DC: American Psychiatric Association.

Anderson, B., Storfer-Isser, A., Taylor, H. G., Rosen, C. L., \& Redline, S. (2009). Associations of executive function with sleepiness and sleep duration in adolescents. Pediatrics, 123, e701-e707. doi:10.1542/peds.2008-1182.

Armstrong, J. M., Ruttle, P. L., Klein, M. H., Essex, M. J., \& Benca, R. M. (2014). Associations of child insomnia, sleep movement, and their persistence with mental health symptoms in childhood and adolescence. Sleep, 37, 901-909. doi:10.5665/sleep.3656.

Aronen, E. T., Paavonen, E. J., Fjallberg, M., Soininen, M., \& Torronen, J. (2000). Sleep and psychiatric symptoms in schoolage children. Journal of the American Academy of Child and Adolescent Psychiatry, 39, 502-508. doi:10.1097/00004583200004000-00020.

Arora, T., Broglia, E., Thomas, G. N., \& Taheri, S. (2014). Associations between specific technologies and adolescent sleep quantity, sleep quality, and parasomnias. Sleep Medicine, 15, 240-247. doi:10.1016/j.sleep.2013.08.799.

Astill, R. G., Van der Heijden, K. B., Van Ijzendoorn, M. H., \& Van Someren, E. J. (2012). Sleep, cognition, and behavioral problems in school-age children: A century of research meta-analyzed. Psychololgical Bulletin, 138, 1109-1138. doi:10.1037/ a0028204.

Bachman, J. G., \& Schulenberg, J. (1993). How part-time work intensity relates to drug use, problem behavior, time use, and satisfaction among high school seniors: Are these consequences or merely correlates. Developmental Psychology, 29, 220-235. doi:10.1037//0012-1649.29.2.220.

Bajoghli, H., Alipouri, A., Holsboer-Trachsler, E., \& Brand, S. (2013). Sleep patterns and psychological functioning in families in northeastern Iran; evidence for similarities between adolescent children and their parents. Journal of Adolescence, 36, 1103-1113. doi:10.1016/j.adolescence.2013.08.016.

Banich, M. T. (2009). Executive function: The search for an integrated account. Current Directions in Psychological Science, 18, 89-94. doi:10.1111/j.1467-8721.2009.01615.x.

Barkley, R. A., Murphy, K. R., \& Kwasnik, D. (1996). Motor vehicle driving competencies and risks in teens and young adults with attention deficit hyperactivity disorder. Pediatrics, 98, 1089-1095.

Barnes, J. C., \& Meldrum, R. C. (2015). The impact of sleep duration on adolescent development: A genetically informed analysis of 
identical twin pairs. Journal of Youth and Adolescence. doi:10. 1007/s10964-014-0137-4.

Bartel, K., Gradisar, M., \& Williamson, P. (2014). Protective and risk factors for adolescent sleep: A meta-analytic review. Sleep Medicine Reviews. doi:10.1016/j.smrv.2014.08.002.

Baum, K. T., Desai, A., Field, J., Miller, L. E., Rausch, J., \& Beebe, D. W. (2014). Sleep restriction worsens mood and emotion regulation in adolescents. Journal of Child Psychology and Psychiatry, 55, 180-190. doi:10.1111/jcpp.12125.

Becker, S. P. (2014). External validity of children's self-reported sleep functioning: Associations with academic, social, and behavioral adjustment. Sleep Medicine, 15, 1094-1100. doi:10. 1016/j.sleep.2014.06.001.

Becker, S. P., \& Kerig, P. K. (2011). Posttraumatic stress symptoms are associated with the frequency and severity of delinquency among detained boys. Journal of Clinical Child and Adolescent Psychology, 40, 765-771. doi:10.1080/15374416.2011.597091.

Becker, S. P., Langberg, J. M., \& Evans, S. W. (2014). Sleep problems predict comorbid externalizing behaviors and depression in young adolescents with attention-deficit/hyperactivity disorder. European Child and Adolescent Psychiatry. doi:10. 1007/s00787-014-0636-6.

Beebe, D. W. (2011). Cognitive, behavioral, and functional consequences of inadequate sleep in children and adolescents. Pediatric Clinics of North America, 58, 649-665. doi:10.1016/ j.pcl.2011.03.002.

Beebe, D. W., Fallone, G., Godiwala, N., Flanigan, M., Martin, D., Schaffner, L., \& Amin, R. (2008). Feasibility and behavioral effects of an at-home multi-night sleep restriction protocol for adolescents. Journal of Child Psychology and Psychiatry, 49, 915-923. doi:10.1111/j.1469-7610.2008.01885.x.

Beebe, D. W., Rose, D., \& Amin, R. (2010). Attention, learning, and arousal of experimentally sleep-restricted adolescents in a simulated classroom. Journal of Adolescent Health, 47, 523-525. doi:10.1016/j.jadohealth.2010.03.005.

Bell, B. G., \& Belsky, J. (2008). Parents, parenting, and children's sleep problems: Exploring reciprocal effects. British Journal of Developmental Psychology, 26, 579-593. doi:10.1348/ $026151008 \times 285651$.

Bootzin, R. R., \& Stevens, S. J. (2005). Adolescents, substance abuse, and the treatment of insomnia and daytime sleepiness. Clinical Psychology Review, 25, 629-644. doi:10.1016/j.cpr.2005.04.007.

Borbély, A. A. (1982). A two process model of sleep regulation. Human Neurobiology, 1, 195-204.

Borbély, A. A., \& Achermann, P. (1999). Sleep homeostasis and models of sleep regulation. Journal of Biological Rhythms, 14 , 557-568. doi:10.1177/074873099129000894.

Borbély, A. A., Achermann, P., Trachsel, L., \& Tobler, I. (1989). Sleep initiation and initial sleep intensity: Interactions of homeostatic and circadian mechanisms. Journal of Biological Rhythms, 4, 149-160. doi:10.1177/074873048900400205.

Brand, S., Gerber, M., Hatzinger, M., Beck, J., \& Holsboer-Trachsler, E. (2009a). Evidence for similarities between adolescents and parents in sleep patterns. Sleep Medicine, 10, 1124-1131. doi:10. 1016/j.sleep.2008.12.013.

Brand, S., Hatzinger, M., Beck, J., \& Holsboer-Trachsler, E. (2009b). Perceived parenting styles, personality traits and sleep patterns in adolescents. Journal of Adolescence, 32, 1189-1207. doi:10. 1016/j.adolescence.2009.01.010.

Braun, A. R., Balkin, T. J., Wesenten, N. J., Carson, R. E., Varga, M., Baldwin, P., et al. (1997). Regional cerebral blood flow throughout the sleep-wake cycle. An H2(15)O PET study. Brain, 120, 1173-1197. doi:10.1093/brain/120.7.1173.

Brković, I., Keresteš, G., \& Levpušček, M. P. (2014). Trajectories of change and relationship between parent-adolescent schoolrelated conflict and academic achievement in early adolescence.
Journal of Early Adolescence, 34, 792-815. doi:10.1177/ 0272431613503213.

Bronfenbrenner, U. (1979). The ecology of human development: Experiments by nature and design. Cambridge, MA: Harvard University Press.

Bronfenbrenner, U. (1992). Ecological systems theory. In V. Ross (Ed.), Six theories of child development: Revised formulations and current issues (pp. 187-249). London: Jessica Kingsley Publishers.

Broyd, S. J., Demanuele, C., Debener, S., Helps, S. K., James, C. J., \& Sonuga-Barke, E. J. (2009). Default-mode brain dysfunction in mental disorders: A systematic review. Neuroscience and Biobehavioral Reviews, 33, 279-296. doi:10.1016/j.neubiorev. 2008.09.002.

Bryant, A. L., Schulenberg, J. E., O’Malley, P. M., Bachman, J. G., \& Johnston, L. D. (2003). How academic achievement, attitudes, and behaviors relate to the course of substance use during adolescence: A 6-year, multiwave national longitudinal study. Journal of Research on Adolescence, 13, 361-397. doi:10.1111/ 1532-7795.1303005.

Bryant, A. L., \& Zimmerman, M. A. (2002). Examining the effects of academic beliefs and behaviors on changes in substance use among urban adolescents. Journal of Educational Psychology, 94, 621-637. doi:10.1037//0022-0663.94.3.621.

Bukowski, W. M., Buhrmester, D., \& Underwood, M. K. (2011). Peer relations as a developmental context. In M. K. Underwood \& L. H. Rosen (Eds.), Social development: Relationships in infancy, childhood, and adolescence (pp. 153-179). New York: Guilford.

Burke, J. D., Loeber, R., \& Lahey, B. B. (2001). Which aspects of ADHD are associated with tobacco use in early adolescence? Journal of Child Psychology and Psychiatry, 42, 493-502. doi:10.1017/S0021963001007132.

Cain, N., \& Gradisar, M. (2010). Electronic media use and sleep in school-aged children and adolescents: A review. Sleep Medicine, 11, 735-742. doi:10.1016/j.sleep.2010.02.006.

Cajochen, C., Krauchi, K., \& Wirz-Justice, A. (2003). Role of melatonin in the regulation of human circadian rhythms and sleep. Journal of Neuroendocrinology, 15, 432-437. doi:10. 1046/j.1365-2826.2003.00989.x.

Calamaro, C. J., Mason, T. B., \& Ratcliffe, S. J. (2009). Adolescents living the 24/7 lifestyle: Effects of caffeine and technology on sleep duration and daytime functioning. Pediatrics, 123, e1005e1010. doi:10.1542/peds.2008-3641.

Campbell, I. G., \& Feinberg, I. (2009). Longitudinal trajectories of non-rapid eye movement delta and theta EEG as indicators of adolescent brain maturation. Proceedings of the National Academy of Sciences, 106, 5177-5180. doi:10.1073/pnas. 0812947106.

Cappuccio, F. P., Taggart, F. M., Kandala, N. B., Currie, A., Peile, E., Stranges, S., \& Miller, M. A. (2008). Meta-analysis of short sleep duration and obesity in children and adults. Sleep, 31, 619-626.

Carrell, S. E., Maghakian, T., \& West, J. E. (2011). A's from Zzzz's? The causal effect of school start time on the academic achievement of adolescents. American Economic Journal-Economic Policy, 3, 62-81. doi:10.1257/Pol.3.3.62.

Carskadon, M. A. (2011). Sleep in adolescents: The perfect storm. Pediatric Clinics of North America, 58, 637-647. doi:10.1016/j. pcl.2011.03.003.

Carskadon, M. A., Harvey, K., Duke, P., Anders, T. F., Litt, I. F., \& Dement, W. C. (1980). Pubertal changes in daytime sleepiness. Sleep, 2, 453-460.

Carskadon, M. A., Wolfson, A. R., Acebo, C., Tzischinsky, O., \& Seifer, R. (1998). Adolescent sleep patterns, circadian timing, and sleepiness at a transition to early school days. Sleep, 21 , $871-881$. 
Castellanos, F. X., Margulies, D. S., Kelly, C., Uddin, L. Q., Ghaffari, M., Kirsch, A., \& Milham, M. P. (2008). Cingulate-precuneus interactions: A new locus of dysfunction in adult attentiondeficit/hyperactivity disorder. Biological Psychiatry, 63, 332-337. doi:10.1016/j.biopsych.2007.06.025.

Castellanos, F. X., Sonuga-Barke, E. J., Scheres, A., Di Martino, A., Hyde, C., \& Walters, J. R. (2005). Varieties of attention-deficit/ hyperactivity disorder-related intra-individual variability. Biological Psychiatry, 57, 1416-1423. doi:10.1016/j.biopsych.2004. 12.005 .

Catrett, C. D., \& Gaultney, J. F. (2009). Possible insomnia predicts some risky behaviors among adolescents when controlling for depressive symptoms. Journal of Genetic Psychology, 170, 287-309. doi:10.1080/00221320903218331.

Charuvastra, A., \& Cloitre, M. (2009). Safe enough to sleep: Sleep disruptions associated with trauma, posttraumatic stress, and anxiety in children and adolescents. Child and Adolescent Psychiatric Clinics of North America, 18, 877-891. doi:10.1016/ j.chc.2009.04.002.

Cicchetti, D., \& Rogosch, F. A. (1996). Equifinality and multifinality in developmental psychopathology. Development and Psychopathology, 8, 597-600. doi:10.1017/S0954579400007318.

Cicchetti, D., \& Rogosch, F. A. (2002). A developmental psychopathology perspective on adolescence. Journal of Consulting and Clinical Psychology, 70, 6-20. doi:10.1037/0022-006X.70.1.6.

Claes, M., Lacourse, E., Ercolani, A. P., Pierro, A., Leone, L., \& Presaghi, F. (2005). Parenting, peer orientation, drug use, and antisocial behavior in late adolescence: A cross-national study. Journal of Youth and Adolescence, 34, 401-411. doi:10.1007/ s10964-005-7258-8.

Clinkinbeard, S. S., Simi, P., Evans, M. K., \& Anderson, A. L. (2011). Sleep and delinquency: Does the amount of sleep matter? Journal of Youth and Adolescence, 40, 916-930. doi:10.1007/ s10964-010-9594-6.

Coghill, D., Soutullo, C., d'Aubuisson, C., Preuss, U., Lindback, T., Silverberg, M., \& Buitelaar, J. (2008). Impact of attentiondeficit/hyperactivity disorder on the patient and family: Results from a European survey. Child and Adolescent Psychiatry and Mental Health, 2, 31. doi:10.1186/1753-2000-2-31.

Cohen-Zion, M., \& Ancoli-Israel, S. (2004). Sleep in children with attention-deficit hyperactivity disorder (ADHD): A review of naturalistic and stimulant intervention studies. Sleep Medicine Reviews, 8, 379-402. doi:10.1016/j.smrv.2004.06.002.

Collins, W. A., \& Steinberg, L. (2008). Adolescent develoment in interpersonal context. In W. Damon, R. M. Lerner, D. Kuhn, R. S. Siegler, \& N. Eisenberg (Eds.), Child and adolescent development: An advanced course (pp. 551-590). Hoboken, NJ: Wiley.

Colrain, I. M., \& Baker, F. C. (2011). Changes in sleep as a function of adolescent development. Neuropsychology Review, 21, 5-21. doi:10.1007/s11065-010-9155-5.

Cooley-Quille, M., \& Lorion, R. (1999). Adolescents exposure to community violence: Sleep and psychophysiological functioning. Journal of Community Psychology, 27, 367-375. doi:10.1002/(Sici)1520-6629(199907)27:4<367:Aid-Jcop1>3.0. Co;2-T.

Cortese, S., Faraone, S. V., Konofal, E., \& Lecendreux, M. (2009). Sleep in children with attention-deficit/hyperactivity disorder: Meta-analysis of subjective and objective studies. Journal of the American Academy of Child and Adolescent Psychiatry, 48, 894-908. doi:10.1097/CHI.0b013e3181ac09c9.

Costello, E. J., Copeland, W., \& Angold, A. (2011). Trends in psychopathology across the adolescent years: What changes when children become adolescents, and when adolescents become adults? Journal of Child Psychology and Psychiatry, 52, 1015-1025. doi:10.1111/j.1469-7610.2011.02446.x.
Curcio, G., Ferrara, M., \& De Gennaro, L. (2006). Sleep loss, learning capacity and academic performance. Sleep Medicine Reviews, 10, 323-337. doi:10.1016/j.smrv.2005.11.001.

Dahl, R. E. (1996). The regulation of sleep and arousal: Development and psychopathology. Development and Psychopathology, 8, 3-27. doi:10.1017/S0954579400006945.

Dahl, R. E., \& El-Sheikh, M. (2007). Considering sleep in a family context: Introduction to the special issue. Journal of Family Psychology, 21, 1-3. doi:10.1037/0893-3200.21.1.1.

Dahl, R. E., \& Lewin, D. S. (2002). Pathways to adolescent health sleep regulation and behavior. Journal of Adolescent Health, 31, 175-184. doi:10.1016/S1054-139X(02)00506-2.

Danielsson, N. S., Harvey, A. G., MacDonald, S., Jansson-Frojmark, M., \& Linton, S. J. (2013). Sleep disturbance and depressive symptoms in adolescence: The role of catastrophic worry. Journal of Youth and Adolescence, 42, 1223-1233. doi:10.1007/ s10964-012-9811-6.

Danner, F., \& Phillips, B. (2008). Adolescent sleep, school start times, and teen motor vehicle crashes. Journal of Clinical Sleep Medicine, 4, 533-535.

De Havas, J. A., Parimal, S., Soon, C. S., \& Chee, M. W. (2012). Sleep deprivation reduces default mode network connectivity and anti-correlation during rest and task performance. Neuroimage, 59, 1745-1751. doi:10.1016/j.neuroimage.2011.08.026.

Deault, L. C. (2010). A systematic review of parenting in relation to the development of comorbidities and functional impairments in children with attention-deficit/hyperactivity disorder (ADHD). Child Psychiatry and Human Development, 41, 168-192. doi:10. 1007/s10578-009-0159-4.

Dewald, J. F., Meijer, A. M., Oort, F. J., Kerkhof, G. A., \& Bogels, S. M. (2010). The influence of sleep quality, sleep duration and sleepiness on school performance in children and adolescents: A meta-analytic review. Sleep Medicine Reviews, 14, 179-189. doi:10.1016/j.smrv.2009.10.004.

Dexter, D., Bijwadia, J., Schilling, D., \& Applebaugh, G. (2003). Sleep, sleepiness and school start times: A preliminary study. WMJ, 102, 44-46.

Diaz-Morales, J. F., Escribano, C., Jankowski, K. S., Vollmer, C., \& Randler, C. (2014). Evening adolescents: The role of family relationships and pubertal development. Journal of Adolescence, 37, 425-432. doi:10.1016/j.adolescence.2014.03.001.

Dishion, T. J., Nelson, S. E., \& Bullock, B. M. (2004). Premature adolescent autonomy: Parent disengagement and deviant peer process in the amplification of problem behaviour. Journal of Adolescence, 27, 515-530. doi:10.1016/j.adolescence.2004.06. 005.

Dishion, T. J., Veronneau, M. H., \& Myers, M. W. (2010). Cascading peer dynamics underlying the progression from problem behavior to violence in early to late adolescence. Development and Psychopathology, 22, 603-619. doi:10.1017/S0954579410000 313.

Do, Y. K., Shin, E., Bautista, M. A., \& Foo, K. (2013). The associations between self-reported sleep duration and adolescent health outcomes: What is the role of time spent on Internet use? Sleep Medicine, 14, 195-200. doi:10.1016/j.sleep.2012.09.004.

Doane, L. D., Gress-Smith, J. L., \& Breitenstein, R. S. (2015). Multimethod assessments of sleep over the transition to college and the associations with depression and anxiety symptoms. Journal of Youth and Adolescence. doi:10.1007/s10964-014-0150-7.

Doane, L. D., \& Thurston, E. C. (2014). Associations among sleep, daily experiences, and loneliness in adolescence: Evidence of moderating and bidirectional pathways. Journal of Adolescence, 37, 145-154. doi:10.1016/j.adolescence.2013.11.009.

Dorofaeff, T. F., \& Denny, S. (2006). Sleep and adolescence. Do New Zealand teenagers get enough? Journal of Paediatrics and Child Health, 42, 515-520. doi:10.1111/j.1440-1754.2006.00914.x. 
Dotterer, A. M., Hoffman, L., Crouter, A. C., \& McHale, S. M. (2008). A longitudinal examination of the bidirectional links between academic achievement and parent-adolescent conflict. Journal of Family Issues, 29, 762-779. doi:10.1177/ $0192513 \times 07309454$.

DuPaul, G. J., \& Langberg, J. M. (2014). Educational impairments in children with ADHD. In R. A. Barkley (Ed.), Attention-deficit/ hyperactivity disorder: A handbook for diagnosis and treatment (4th ed.). New York: Guilford.

Eaton, D. K., McKnight-Eily, L. R., Lowry, R., Perry, G. S., PresleyCantrell, L., \& Croft, J. B. (2010). Prevalence of insufficient, borderline, and optimal hours of sleep among high school students-United States, 2007. Journal of Adolescent Health, 46, 399-401. doi:10.1016/j.jadohealth.2009.10.011.

Eccles, J. S., Barber, B. L., Stone, M., \& Hunt, J. (2003). Extracurricular activities and adolescent development. Journal of Social Issues, 59, 865-889. doi:10.1046/j.0022-4537.2003. 00095.x.

Edwards, F. (2012). Early to rise? The effect of daily start times on academic performance. Economics of Education Review, 31, 970-983. doi:10.1016/j.econedurev.2012.07.006.

Eggermont, S., \& Van den Bulck, J. (2006). Nodding off or switching off? The use of popular media as a sleep aid in secondary-school children. Journal of Paediatrics and Child Health, 42, 428-433. doi:10.1111/j.1440-1754.2006.00892.x.

Elder, G. J., Wetherell, M. A., Barclay, N. L., \& Ellis, J. G. (2014). The cortisol awakening response: Applications and implications for sleep medicine. Sleep Medicine Reviews, 18, 215-224. doi:10.1016/j.smrv.2013.05.001.

Fair, D. A., Posner, J., Nagel, B. J., Bathula, D., Dias, T. G., Mills, K., et al. (2010). Atypical default network connectivity in youth with attention-deficit/hyperactivity disorder. Biological Psychiatry, 68, 1084-1091. doi:10.1016/j.biopsych.2010.07.003.

Fallone, G., Acebo, C., Arnedt, J. T., Seifer, R., \& Carskadon, M. A. (2001). Effects of acute sleep restriction on behavior, sustained attention, and response inhibition in children. Perceptual and Motor Skills, 93, 213-229. doi:10.2466/pms.2001.93.1.213.

Fallone, G., Acebo, C., Seifer, R., \& Carskadon, M. A. (2005). Experimental restriction of sleep opportunity in children: Effects on teacher ratings. Sleep, 28, 1561-1567.

Feinberg, I., \& Campbell, I. G. (2010). Sleep EEG changes during adolescence: An index of a fundamental brain reorganization. Brain and Cognition, 72, 56-65. doi:10.1016/j.bandc.2009.09. 008.

Feinberg, I., Higgins, L. M., Khaw, W. Y., \& Campbell, I. G. (2006). The adolescent decline of NREM delta, an indicator of brain maturation, is linked to age and sex but not to pubertal stage. American Journal of Physiology Regulatory, Integrative and Comparative Physiology, 291, R1724-R1729. doi:10.1152/ ajpregu.00293.2006

Fischer, F. M., Nagai, R., \& Teixeira, L. R. (2008). Explaining sleep duration in adolescents: the impact of socio-demographic and lifestyle factors and working status. Chronobiology International, 25, 359-372. doi:10.1080/07420520802110639.

Fite, P. J., Becker, S. P., Rubens, S. L., \& Cheatham-Johnson, R. (2014). Anxiety symptoms account for the link between reactive aggression and sleep problems among Latino adolescents. Child and Youth Care Forum. doi:10.1007/s10566-014-9288-4.

Fontaine, R. G., Yang, C., Burks, V. S., Dodge, K. A., Price, J. M., Pettit, G. S., \& Bates, J. E. (2009). Loneliness as a partial mediator of the relation between low social preference in childhood and anxious/depressed symptoms in adolescence. Development and Psychopathology, 21, 479-491. doi:10.1017/ S0954579409000261.

Fredriksen, K., Rhodes, J., Reddy, R., \& Way, N. (2004). Sleepless in Chicago: Tracking the effects of adolescent sleep loss during the middle school years. Child Development, 75, 84-95. doi:10. 1111/j.1467-8624.2004.00655.x.

Fukuda, K., \& Ishihara, K. (2002). Routine evening naps and nighttime sleep patterns in junior high and high school students. Psychiatry and Clinical Neurosciences, 56, 229-230. doi:10. 1046/j.1440-1819.2002.00986.x.

Fuligni, A. J., \& Hardway, C. (2006). Daily variation in adolescents' sleep, activities, and psychological well-being. Journal of Research on Adolescence, 16, 353-377. doi:10.1111/j.15327795.2006.00498.x.

Galambos, N. L., Barker, E. T., \& Almeida, D. M. (2003). Parents do matter: Trajectories of change in externalizing and internalizing problems in early adolescence. Child Development, 74, 578-594. doi:10.1111/1467-8624.7402017.

Gangwisch, J. E., Babiss, L. A., Malaspina, D., Turner, J. B., Zammit, G. K., \& Posner, K. (2010). Earlier parental set bedtimes as a protective factor against depression and suicidal ideation. Sleep, 33, 97-106.

Gardner, D. M., \& Gerdes, A. C. (2013). A review of peer relationships and friendships in youth with ADHD. Journal of Attention Disorders. doi:10.1177/1087054713501552.

Giedd, J. N. (2004). Structural magnetic resonance imaging of the adolescent brain. Annals of the New York Academy of Sciences, 1021, 77-85. doi:10.1196/annals.1308.009.

Gillen-O’Neel, C., Huynh, V. W., \& Fuligni, A. J. (2013). To study or to sleep? The academic costs of extra studying at the expense of sleep. Child Development, 84, 133-142. doi:10.1111/j.14678624.2012.01834.x.

Goldstein, T. R., Bridge, J. A., \& Brent, D. A. (2008). Sleep disturbance preceding completed suicide in adolescents. Journal of Consulting and Clinical Psychology, 76, 84-91. doi:10.1037/ 0022-006X.76.1.84.

Gradisar, M., Gardner, G., \& Dohnt, H. (2011). Recent worldwide sleep patterns and problems during adolescence: A review and meta-analysis of age, region, and sleep. Sleep Medicine, 12, 110-118. doi:10.1016/j.sleep.2010.11.008.

Gregory, A. M., Caspi, A., Eley, T. C., Moffitt, T. E., Oconnor, T. G., \& Poulton, R. (2005). Prospective longitudinal associations between persistent sleep problems in childhood and anxiety and depression disorders in adulthood. Journal of Abnormal Child Psychology, 33, 157-163. doi:10.1007/s10802-005-1824-0.

Gregory, A. M., \& O'Connor, T. G. (2002). Sleep problems in childhood: A longitudinal study of developmental change and association with behavioral problems. Journal of the American Academy of Child and Adolescent Psychiatry, 41, 964-971. doi:10.1097/00004583-200208000-00015.

Gregory, A. M., \& Sadeh, A. (2012). Sleep, emotional and behavioral difficulties in children and adolescents. Sleep Medicine Reviews, 16, 129-136. doi:10.1016/j.smrv.2011.03.007.

Gregory, A. M., Van der Ende, J., Willis, T. A., \& Verhulst, F. C. (2008). Parent-reported sleep problems during development and self-reported anxiety/depression, attention problems, and aggressive behavior later in life. Archives of Pediatrics and Adolescent Medicine, 162, 330-335. doi:10.1001/archpedi.162.4.330.

Gruber, R. (2009). Sleep characteristics of children and adolescents with attention deficit-hyperactivity disorder. Child and Adolescent Psychiatric Clinics of North America, 18, 863-876. doi:10. 1016/j.chc.2009.04.011.

Gruber, R., Fontil, L., Bergmame, L., Wiebe, S. T., Amsel, R., Frenette, S., \& Carrier, J. (2012). Contributions of circadian tendencies and behavioral problems to sleep onset problems of children with ADHD. BMC Psychiatry, 12, 212. doi:10.1186/ 1471-244X-12-212.

Gruber, R., \& Sadeh, A. (2004). Sleep and neurobehavioral functioning in boys with attention-deficit/hyperactivity disorder and no reported breathing problems. Sleep, 27, 267-273. 
Gruber, R., Sadeh, A., \& Raviv, A. (2000). Instability of sleep patterns in children with attention-deficit/hyperactivity disorder. Journal of the American Academy of Child and Adolescent Psychiatry, 39, 495-501. doi:10.1097/00004583-20000400000019.

Gruber, R., Wiebe, S., Montecalvo, L., Brunetti, B., Amsel, R., \& Carrier, J. (2011). Impact of sleep restriction on neurobehavioral functioning of children with attention deficit hyperactivity disorder. Sleep, 34, 315-323.

Guidolin, M., \& Gradisar, M. (2012). Is shortened sleep duration a risk factor for overweight and obesity during adolescence? A review of the empirical literature. Sleep Medicine, 13, 779-786. doi:10.1016/j.sleep.2012.03.016.

Gujar, N., Yoo, S. S., Hu, P., \& Walker, M. P. (2010). The unrested resting brain: sleep deprivation alters activity within the defaultmode network. Journal of Cognitive Neuroscience, 22, 1637-1648. doi:10.1162/jocn.2009.21331.

Hale, L., \& Guan, S. (2014). Screen time and sleep among schoolaged children and adolescents: A systematic literature review. Sleep Medicine Reviews. doi:10.1016/j.smrv.2014.07.007.

Hansen, M., Janssen, I., Schiff, A., Zee, P. C., \& Dubocovich, M. L. (2005). The impact of school daily schedule on adolescent sleep. Pediatrics, 115, 1555-1561. doi:10.1542/peds.2004-1649.

Hansen, B. H., Skirbekk, B., Oerbeck, B., Richter, J., \& Kristensen, H. (2011). Comparison of sleep problems in children with anxiety and attention deficit/hyperactivity disorders. European Child and Adolescent Psychiatry, 20, 321-330. doi:10.1007/ s00787-011-0179-z.

Hansen, B. H., Skirbekk, B., Oerbeck, B., Wentzel-Larsen, T., \& Kristensen, H. (2014). Associations between sleep problems and attentional and behavioral functioning in children with anxiety disorders and ADHD. Behavioral Sleep Medicine, 12, 53-68. doi:10.1080/15402002.2013.764525.

Harris, R. A., Qualter, P., \& Robinson, S. J. (2013). Loneliness trajectories from middle childhood to pre-adolescence: Impact on perceived health and sleep disturbance. Journal of Adolescence, 36, 1295-1304. doi:10.1016/j.adolescence.2012.12.009.

Hart, C. N., Cairns, A., \& Jelalian, E. (2011). Sleep and obesity in children and adolescents. Pediatric Clinics of North America, 58, 715-733. doi:10.1016/j.pcl.2011.03.007.

Helsen, M., Vollebergh, W., \& Meeus, W. (2000). Social support from parents and friends and emotional problems in adolescence. Journal of Youth and Adolescence, 29, 319-335. doi:10.1023/A: 1005147708827.

Hildenbrand, A. K., Daly, B. P., Nicholls, E., Brooks-Holliday, S., \& Kloss, J. D. (2013). Increased risk for school violence-related behaviors among adolescents with insufficient sleep. Journal of School Health, 83, 408-414. doi:10.1111/josh.12044.

Hinshaw, S. P., Owens, E. B., Zalecki, C., Huggins, S. P., Montenegro-Nevado, A. J., Schrodek, E., \& Swanson, E. N. (2012). Prospective follow-up of girls with attention-deficit/ hyperactivity disorder into early adulthood: Continuing impairment includes elevated risk for suicide attempts and self-injury. Journal of Consulting and Clinical Psychology, 80, 1041-1051. doi:10.1037/a0029451.

Hoeve, M., Dubas, J. S., Eichelsheim, V. I., van der Laan, P. H., Smeenk, W., \& Gerris, J. R. (2009). The relationship between parenting and delinquency: A meta-analysis. Journal of Abnormal Child Psychology, 37, 749-775. doi:10.1007/s10802-0099310-8.

Hvolby, A., Jorgensen, J., \& Bilenberg, N. (2008). Actigraphic and parental reports of sleep difficulties in children with attentiondeficit/hyperactivity disorder. Archives of Pediatrics and Adolescent Medicine, 162, 323-329. doi:10.1001/archpedi.162.4. 323.
Ireland, J. L., \& Culpin, V. (2006). The relationship between sleeping problems and aggression, anger, and impulsivity in a population of juvenile and young offenders. Journal of Adolescent Health, 38, 649-655. doi:10.1016/j.jadohealth.2005.05.027.

James, J. E., Kristjansson, A. L., \& Sigfusdottir, I. D. (2011). Adolescent substance use, sleep, and academic achievement: Evidence of harm due to caffeine. Journal of Adolescence, 34, 665-673. doi:10.1016/j.adolescence.2010.09.006.

Jarrin, D. C., McGrath, J. J., Poirier, P., \& QUALITY Cohort Collaborative Group. (2015). Autonomic dysfunction: A possible pathophysiological pathway underlying the association between sleep and obesity in children at-risk for obesity. Journal of Youth and Adolescence. doi:10.1007/s10964-014-0235-3.

Jenni, O. G., Achermann, P., \& Carskadon, M. A. (2005). Homeostatic sleep regulation in adolescents. Sleep, 28, 14461454.

Johnson, E. O., \& Breslau, N. (2001). Sleep problems and substance use in adolescence. Drug and Alcohol Dependence, 64, 1-7. doi:10.1016/S0376-8716(00)00222-2.

Johnson, J. G., Cohen, P., Kasen, S., First, M. B., \& Brook, J. S. (2004). Association between television viewing and sleep problems during adolescence and early adulthood. Archives of Pediatrics and Adolescent Medicine, 158, 562-568. doi:10.1001/ archpedi.158.6.562.

Johnson, E. O., Roth, T., \& Breslau, N. (2006a). The association of insomnia with anxiety disorders and depression: Exploration of the direction of risk. Journal of Psychiatric Research, 40, 700-708. doi:10.1016/j.jpsychires.2006.07.008.

Johnson, E. O., Roth, T., Schultz, L., \& Breslau, N. (2006b). Epidemiology of DSM-IV insomnia in adolescence: Lifetime prevalence, chronicity, and an emergent gender difference. Pediatrics, 117, e247-e256. doi:10.1542/peds.2004-2629.

Kaneita, Y., Ohida, T., Osaki, Y., Tanihata, T., Minowa, M., Suzuki, K., et al. (2006). Insomnia among Japanese adolescents: A nationwide representative survey. Sleep, 29, 1543-1550.

Kelly, R. J., \& El-Sheikh, M. (2014). Reciprocal relations between children's sleep and their adjustment over time. Developmental Psychology, 50, 1137-1147. doi:10.1037/a0034501.

Kelly, R. J., Marks, B. T., \& El-Sheikh, M. (2014). Longitudinal relations between parent-child conflict and children's adjustment: The role of children's sleep. Journal of Abnormal Child Psychology, 42, 1175-1185. doi:10.1007/s10802-014-9863-z.

Kerig, P. K., \& Becker, S. P. (2010). From internalizing to externalizing: Theoretical models of the processes linking PTSD to juvenile delinquency. In S. J. Egan (Ed.), Post-traumatic stress disorder (PTSD): Causes, symptoms and treatment (pp. 33-78). Hauppauge, NY: Nova.

Kerig, P. K., \& Becker, S. P. (2015). Early abuse and neglect as risk factors for the development of criminal and antisocial behavior. In J. Morizot \& L. Kazemian (Eds.), The development of criminal and antisocial behavior: Theory, research, and practical applications (pp. 181-199). New York: Springer.

King, D. L., Gradisar, M., Drummond, A., Lovato, N., Wessel, J., Micic, G., et al. (2013). The impact of prolonged violent videogaming on adolescent sleep: An experimental study. Journal of Sleep Research, 22, 137-143. doi:10.1111/j.1365-2869.2012. 01060.x.

Kirby, M., Maggi, S., \& D’ Angiulli, A. (2011). School start times and the sleep-wake cycle of adolescents: A review and critical evaluation of available evidence. Educational Researcher, 40, 56-61. doi:10.3102/0013189x11402323.

Kirmil-Gray, K., Eagleston, J. R., Gibson, E., \& Thoresen, C. E. (1984). Sleep disturbance in adolescents: Sleep quality, sleep habits, beliefs about sleep, and daytime functioning. Journal of Youth and Adolescence, 13, 375-384. doi:10.1007/BF02088636. 
Kirov, R., \& Brand, S. (2014). Sleep problems and their effect in ADHD. Expert Review of Neurotherapeutics, 14, 287-299. doi:10.1586/14737175.2014.885382.

Klerman, E. B., Gershengorn, H. B., Duffy, J. F., \& Kronauer, R. E. (2002). Comparisons of the variability of three markers of the human circadian pacemaker. Journal of Biological Rhythms, 17, 181-193.

Kliewer, W., \& Lepore, S. J. (2015). Exposure to violence, social cognitive processing, and sleep problems in urban adolescents. Journal of Youth and Adolescence. doi:10.1007/s10964-0140184-x.

Kopasz, M., Loessl, B., Hornyak, M., Riemann, D., Nissen, C., Piosczyk, H., \& Voderholzer, U. (2010). Sleep and memory in healthy children and adolescents: A critical review. Sleep Medicine Reviews, 14, 167-177. doi:10.1016/j.smrv.2009.10. 006.

Košćec, A., Radošević-Vidaček, B., \& Bakotić, M. (2014). Morningness-eveningness and sleep patterns of adolescents attending school in two rotating shifts. Chronobiology International, 31, 52-63. doi:10.3109/07420528.2013.821128.

Kouzma, N. M., \& Kennedy, G. A. (2002). Homework, stress, and mood disturbance in senior high school students. Psychological Reports, 91, 193-198. doi:10.2466/pr0.2002.91.1.193.

Kubiszewski, V., Fontaine, R., Potard, C., \& Gimenes, G. (2014). Bullying, sleep/wake patterns and subjective sleep disorders: Findings from a cross-sectional survey. Chronobiology International, 31, 542-553. doi:10.3109/07420528.2013.877475.

Kuo, S. I., Updegraff, K. A., Zeiders, K. H., McHale, S. M., UmanaTaylor, A. J., \& De Jesus, S. A. (2015). Mexican American adolescents' sleep patterns: Contextual correlates and implications for health and adjustment in young adulthood. Journal of Youth and Adolescence. doi:10.1007/s10964-014-0156-1.

Ladd, G. W., \& Ettekal, I. (2013). Peer-related loneliness across early to late adolescence: Normative trends, intra-individual trajectories, and links with depressive symptoms. Journal of Adolescence, 36, 1269-1282. doi:10.1016/j.adolescence.2013.05.004.

Langberg, J. M., Dvorsky, M. R., Becker, S. P., \& Molitor, S. J. (2014a). The impact of daytime sleepiness on the school performance of college students with attention deficit hyperactivity disorder (ADHD): A prospective longitudinal study. Journal of Sleep Research, 23, 318-325. doi:10.1111/jsr.12121.

Langberg, J. M., Dvorsky, M. R., Becker, S. P., \& Molitor, S. J. (2014b). School maladjustment and external locus of control predict the daytime sleepiness of college students with ADHD. Journal of Attention Disorders. doi:10.1177/108705471452 9818.

Langberg, J. M., Dvorsky, M. R., \& Evans, S. W. (2013a). What specific facets of executive function are associated with academic functioning in youth with attention-deficit/hyperactivity disorder? Journal of Abnormal Child Psychology, 41, 1145-1159. doi:10.1007/s10802-013-9750-z.

Langberg, J. M., Dvorsky, M. R., Marshall, S., \& Evans, S. W. (2013b). Clinical implications of daytime sleepiness for the academic performance of middle school-aged adolescents with attention deficit hyperactivity disorder. Journal of Sleep Research, 22, 542-548. doi:10.1111/jsr.12049.

Larson, R. W. (2001). How US children and adolescents spend time: What it does (and doesn't) tell us about their development. Current Directions in Psychological Science, 10, 160-164. doi:10.1111/1467-8721.00139.

Larson, K., Russ, S. A., Kahn, R. S., \& Halfon, N. (2011). Patterns of comorbidity, functioning, and service use for US children with ADHD, 2007. Pediatrics, 127, 462-470. doi:10.1542/peds.20100165 .

Lasgaard, M., Goossens, L., \& Elklit, A. (2011). Loneliness, depressive symptomatology, and suicide ideation in adolescence: Cross- sectional and longitudinal analyses. Journal of Abnormal Child Psychology, 39, 137-150. doi:10.1007/s10802-010-9442-x.

Laursen, B., \& Hartl, A. C. (2013). Understanding loneliness during adolescence: Developmental changes that increase the risk of perceived social isolation. Journal of Adolescence, 36, 1261-1268. doi:10.1016/j.adolescence.2013.06.003.

Lazaratou, H., Dikeos, D. G., Anagnostopoulos, D. C., Sbokou, O., \& Soldatos, C. R. (2005). Sleep problems in adolescence. A study of senior high school students in Greece. European Child and Adolescent Psychiatry, 14, 237-243. doi:10.1007/s00787-0050460-0.

Lee, S. S., Humphreys, K. L., Flory, K., Liu, R., \& Glass, K. (2011). Prospective association of childhood attention-deficit/hyperactivity disorder (ADHD) and substance use and abuse/dependence: A meta-analytic review. Clinical Psychology Review, 31, 328-341. doi:10.1016/j.cpr.2011.01.006.

Lemola, S., Perkinson-Gloor, N., Brand, S., Dewald-Kaufmann, J. F., \& Grob, A. (2015). Adolescents' electronic media use at night, sleep disturbance, and depressive symptoms in the smartphone age. Journal of Youth and Adolescence. doi:10.1007/s10964014-0176-x.

Lemola, S., Schwarz, B., \& Siffert, A. (2012). Interparental conflict and early adolescents' aggression: Is irregular sleep a vulnerability factor? Journal of Adolescence, 35, 97-105. doi:10.1016/j. adolescence.2011.06.001.

Lemos, N., Weissheimer, J., \& Ribeiro, S. (2014). Naps in school can enhance the duration of declarative memories learned by adolescents. Frontiers in Systems Neuroscience, 8, 103. doi:10. 3389/fnsys.2014.00103.

Leone, C. M., \& Richards, H. (1989). Classwork and homework in early adolescence: The ecology of achievement. Journal of Youth and Adolescence, 18, 531-548. doi:10.1007/BF02139072.

Lepore, S. J., \& Kliewer, W. (2013). Violence exposure, sleep disturbance, and poor academic performance in middle school. Journal of Abnormal Child Psychology, 41, 1179-1189. doi:10. 1007/s10802-013-9709-0.

Lewinsohn, P. M., Clarke, G. N., Seeley, J. R., \& Rohde, P. (1994). Major depression in community adolescents: Age at onset, episode duration, and time to recurrence. Journal of the American Academy of Child and Adolescent Psychiatry, 33, 809-818. doi:10.1097/00004583-199407000-00006.

Lin, W. H., \& Yi, C. C. (2015). Unhealthy sleep practices, conduct problems, and daytime functioning during adolescence. Journal of Youth and Adolescence. doi:10.1007/s10964-014-0169-9.

Liu, X. (2004). Sleep and adolescent suicidal behavior. Sleep, 27, 1351-1358.

Logan, D. E., Sieberg, C. B., Conroy, C., Smith, K., Odell, S., \& Sethna, N. (2015). Changes in sleep habits in adolescents during intensive interdisciplinary pediatric pain rehabilitation. Journal of Youth and Adolescence. doi:10.1007/s10964-014-0155-2.

Lovato, N., \& Gradisar, M. (2014). A meta-analysis and model of the relationship between sleep and depression in adolescents: Recommendations for future research and clinical practice. Sleep Medicine Reviews, 18, 521-529. doi:10.1016/j.smrv.2014.03.006.

Lufi, D., Tzischinsky, O., \& Hadar, S. (2011). Delaying school starting time by one hour: Some effects on attention levels in adolescents. Journal of Clinical Sleep Medicine, 7, 137-143.

Lundh, L. G., Bjarehed, J., \& Wangby-Lundh, M. (2013). Poor sleep as a risk factor for nonsuicidal self-injury in adolescent girls. Journal of Psychopathology and Behavioral Assessment, 35, 85-92. doi:10.1007/s10862-012-9307-4.

Lycett, K., Mensah, F. K., Hiscock, H., \& Sciberras, E. (2014a). A prospective study of sleep problems in children with ADHD. Sleep Medicine, 15, 1354-1361. doi:10.1016/j.sleep.2014.06.004.

Lycett, K., Sciberras, E., Mensah, F. K., \& Hiscock, H. (2014b). Behavioral sleep problems and internalizing and externalizing 
comorbidities in children with attention-deficit/hyperactivity disorder. European Child and Adolescent Psychiatry. doi:10. 1007/s00787-014-0530-2.

Mahon, N. E. (1994). Loneliness and sleep during adolescence. Perceptual and Motor Skills, 78, 227-231. doi:10.2466/pms. 1994.78.1.227.

Manni, R., Ratti, M. T., Marchioni, E., Castelnovo, G., Murelli, R., Sartori, I., et al. (1997). Poor sleep in adolescents: A study of 869 17-year-old Italian secondary school students. Journal of Sleep Research, 6, 44-49.

Marshal, M. P., Molina, B. S. G., \& Pelham, W. E. (2003). Childhood ADHD and adolescent substance use: An examination of deviant peer group affiliation as a risk factor. Psychology of Addictive Behaviors, 17, 293-302. doi:10.1037/0893-164x.17.4.293.

Maslowsky, J., \& Ozer, E. J. (2014). Developmental trends in sleep duration in adolescence and young adulthood: Evidence from a national United States sample. Journal of Adolescent Health, 54, 691-697. doi:10.1016/j.jadohealth.2013.10.201.

Maume, D. J. (2013). Social ties and adolescent sleep disruption. Journal of Health and Social Behavior, 54, 498-515. doi:10. 1177/0022146513498512.

McGlinchey, E. L., \& Harvey, A. G. (2015). Risk behaviors and negative health outcomes for adolescents with late bedtimes. Journal of Youth and Adolescence. doi:10.1007/s10964-0140110-2.

McKnight-Eily, L. R., Eaton, D. K., Lowry, R., Croft, J. B., PresleyCantrell, L., \& Perry, G. S. (2011). Relationships between hours of sleep and health-risk behaviors in US adolescent students. Preventive Medicine, 53, 271-273. doi:10.1016/j.ypmed.2011. 06.020.

McNamara, P., Andresen, J., Clark, J., Zborowski, M., \& Duffy, C. A. (2001). Impact of attachment styles on dream recall and dream content: A test of the attachment hypothesis of REM sleep. Journal of Sleep Research, 10, 117-127. doi:10.1046/j.13652869.2001.00244.x.

McRae, K., Gross, J. J., Weber, J., Robertson, E. R., Sokol-Hessner, P., Ray, R. D., et al. (2012). The development of emotion regulation: An fMRI study of cognitive reappraisal in children, adolescents and young adults. Social Cognitive and Affective Neuroscience, 7, 11-22. doi:10.1093/scan/nsr093.

Meijer, A. M., Reitz, E., Dekovic, M., van den Wittenboer, G. L., \& Stoel, R. D. (2010). Longitudinal relations between sleep quality, time in bed and adolescent problem behaviour. Journal of Child Psychology and Psychiatry, 51, 1278-1286. doi:10.1111/j.14697610.2010.02261.x.

Meldrum, R. C., Barnes, J. C., \& Hay, C. (2015). Sleep deprivation, low self-control, and delinquency: A test of the strength model of self-control. Journal of Youth and Adolescence. doi:10.1007/ s10964-013-0024-4.

Meltzer, L. J., \& Montgomery-Downs, H. E. (2011). Sleep in the family. Pediatric Clinics of North America, 58, 765-774. doi:10. 1016/j.pcl.2011.03.010.

Merikangas, K. R., He, J. P., Burstein, M., Swanson, S. A., Avenevoli, S., Cui, L., et al. (2010). Lifetime prevalence of mental disorders in U.S. adolescents: Results from the National Comorbidity Survey Replication-Adolescent Supplement (NCSA). Journal of the American Academy of Child and Adolescent Psychiatry, 49, 980-989. doi:10.1016/j.jaac.2010.05.017.

Michels, N., Clays, E., De Buyzere, M., Vanaelst, B., De Henauw, S., \& Sioen, I. (2013). Children's sleep and autonomic function: low sleep quality has an impact on heart rate variability. Sleep, 36, 1939-1946. doi:10.5665/sleep.3234.

Miller, K., Danner, F., \& Staten, R. (2008). Relationship of work hours with selected health behaviors and academic progress among a college student cohort. Journal of American College Health, 56, 675-679. doi:10.3200/JACH.56.6.675-679.
Molina, B. S., \& Pelham, W. E, Jr. (2003). Childhood predictors of adolescent substance use in a longitudinal study of children with ADHD. Journal of Abnormal Psychology, 112, 497-507. doi:10. 1037/0021-843X.112.3.497.

Moore, E., Gaskin, C., \& Indig, D. (2013). Childhood maltreatment and post-traumatic stress disorder among incarcerated young offenders. Child Abuse and Neglect, 37, 861-870. doi:10.1016/j. chiabu.2013.07.012.

Moore, M., Kirchner, H. L., Drotar, D., Johnson, N., Rosen, C., Ancoli-Israel, S., \& Redline, S. (2009). Relationships among sleepiness, sleep time, and psychological functioning in adolescents. Journal of Pediatric Psychology, 34, 1175-1183. doi:10. 1093/jpepsy/jsp039.

Moreau, V., Rouleau, N., \& Morin, C. M. (2013). Sleep, attention, and executive functioning in children with attention-deficit/ hyperactivity disorder. Archives of Clinical Neuropsychology, 28, 692-699. doi:10.1093/arclin/act051.

Moreau, V., Rouleau, N., \& Morin, C. M. (2014). Sleep of children with attention deficit hyperactivity disorder: Actigraphic and parental reports. Behavioral Sleep Medicine, 12, 69-83. doi:10. 1080/15402002.2013.764526.

Mrug, S., Madan, A., \& Windle, M. (2012). Temperament alters susceptibility to negative peer influence in early adolescence. Journal of Abnormal Child Psychology, 40, 201-209. doi:10. 1007/s10802-011-9550-2.

Munezawa, T., Kaneita, Y., Osaki, Y., Kanda, H., Minowa, M., Suzuki, K., et al. (2011). The association between use of mobile phones after lights out and sleep disturbances among Japanese adolescents: A nationwide cross-sectional survey. Sleep, 34, 1013-1020. doi:10.5665/SLEEP.1152.

Muro, A., Goma-i-Freixanet, M., \& Adan, A. (2012). Circadian typology and sensation seeking in adolescents. Chronobiology International, 29, 1376-1382. doi:10.3109/07420528.2012.728665.

Muzur, A., Pace-Schott, E. F., \& Hobson, J. A. (2002). The prefrontal cortex in sleep. Trends in Cognitive Science, 6, 475-481. doi:10. 1016/S1364-6613(02)01992-7.

National Sleep Foundation. (2006). 2006 Sleep in America Poll. Washington, DC: National Sleep Foundation.

Negriff, S., Dorn, L. D., Pabst, S. R., \& Susman, E. J. (2011). Morningness/eveningness, pubertal timing, and substance use in adolescent girls. Psychiatry Research, 185, 408-413. doi:10. 1016/j.psychres.2010.07.006.

Noble, G. S., O'Laughlin, L., \& Brubaker, B. (2012). Attention deficit hyperactivity disorder and sleep disturbances: Consideration of parental influence. Behavioral Sleep Medicine, 10, 41-53. doi:10.1080/15402002.2012.636274.

Noland, H., Price, J. H., Dake, J., \& Telljohann, S. K. (2009). Adolescents' sleep behaviors and perceptions of sleep. Journal of School Health, 79, 224-230. doi:10.1111/j.1746-1561.2009. 00402.x.

O'Brien, E. M., \& Mindell, J. A. (2005). Sleep and risk-taking behavior in adolescents. Behavioral Sleep Medicine, 3, 113-133. doi:10.1207/s15402010bsm0303_1.

O'Callaghan, F. V., Al Mamun, A., O'Callaghan, M., Clavarino, A., Williams, G. M., Bor, W., et al. (2010). The link between sleep problems in infancy and early childhood and attention problems at 5 and 14 years: Evidence from a birth cohort study. Early Human Development, 86(7), 419-424. doi:10.1016/j.earlhumdev.2010. 05.020 .

Ochsner, K. N., \& Gross, J. J. (2005). The cognitive control of emotion. Trends in Cognitive Science, 9, 242-249. doi:10.1016/j. tics.2005.03.010.

Ohayon, M. M., Carskadon, M. A., Guilleminault, C., \& Vitiello, M. V. (2004). Meta-analysis of quantitative sleep parameters from childhood to old age in healthy individuals: Developing normative sleep values across the human lifespan. Sleep, 27, 1255-1273. 
Olds, T., Blunden, S., Petkov, J., \& Forchino, F. (2010). The relationships between sex, age, geography and time in bed in adolescents: A meta-analysis of data from 23 countries. Sleep Medicine Reviews, 14, 371-378. doi:10.1016/j.smrv.2009.12. 002.

Owens, J., \& Adolescent Sleep Working Group. (2014). Insufficient sleep in adolescents and young adults: An update on causes and consequences. Pediatrics, 134, e921-e932. doi:10.1542/peds. 2014-1696.

Owens, J. A., Belon, K., \& Moss, P. (2010). Impact of delaying school start time on adolescent sleep, mood, and behavior. Archives of Pediatrics and Adolescent Medicine, 164, 608-614. doi:10.1001/archpediatrics.2010.96.

Owens, J., Gruber, R., Brown, T., Corkum, P., Cortese, S., O'Brien, L., et al. (2013). Future research directions in sleep and ADHD: Report of a consensus working group. Journal of Attention Disorders, 17, 550-564. doi:10.1177/1087054712457992.

Paavonen, E. J., Raikkonen, K., Lahti, J., Komsi, N., Heinonen, K., Pesonen, A. K., et al. (2009). Short sleep duration and behavioral symptoms of attention-deficit/hyperactivity disorder in healthy 7- to 8-year-old children. Pediatrics, 123, e857-e864. doi:10. 1542/peds.2008-2164.

Pasch, K. E., Laska, M. N., Lytle, L. A., \& Moe, S. G. (2010). Adolescent sleep, risk behaviors, and depressive symptoms: are they linked? American Journal of Health Behavior, 34, 237-248.

Pasch, K. E., Latimer, L. A., Cance, J. D., Moe, S. G., \& Lytle, L. A. (2012). Longitudinal bi-directional relationships between sleep and youth substance use. Journal of Youth and Adolescence, 41, 1184-1196. doi:10.1007/s10964-012-9784-5.

Peach, H. D., \& Gaultney, J. F. (2013). Sleep, impulse control, and sensation-seeking predict delinquent behavior in adolescents, emerging adults, and adults. Journal of Adolescent Health, 53, 293-299. doi:10.1016/j.jadohealth.2013.03.012.

Peach, H., Gaultney, J. F., \& Reeve, C. L. (2015). Sleep characteristics, body mass index, and risk for hypertension in young adolescents. Journal of Youth and Adolescence. doi:10.1007/ s10964-014-0149-0.

Pennington, B. F., \& Ozonoff, S. (1996). Executive functions and developmental psychopathology. Journal of Child Psychology and Psychiatry, 37, 51-87. doi:10.1111/j.1469-7610.1996. tb01380.x

Pesonen, A. K., Martikainen, S., Heinonen, K., Wehkalampi, K., Lahti, J., Kajantie, E., \& Raikkonen, K. (2014). Continuity and change in poor sleep from childhood to early adolescence. Sleep, 37, 289-297. doi:10.5665/sleep.3400.

Pieters, S., Burk, W. J., Van der Vorst, H., Dahl, R. E., Wiers, R. W., \& Engels, R. C. (2015). Prospective relationships between sleep problems and substance use, internalizing and externalizing problems. Journal of Youth and Adolescence. doi:10.1007/ s10964-014-0213-9.

Pieters, S., Van Der Vorst, H., Burk, W. J., Wiers, R. W., \& Engels, R. C. (2010). Puberty-dependent sleep regulation and alcohol use in early adolescents. Alcoholism, Clinical and Experimental Research, 34, 1512-1518. doi:10.1111/j.1530-0277.2010.01235.x.

Power, T. J., Karustis, J. L., \& Habboushe, D. F. (2001). Homework success for children with ADHD: A family-school intervention program. New York: Guilford Press.

Power, T. J., Werba, B. E., Watkins, M. W., Angelucci, J. G., \& Eiraldi, R. B. (2006). Patterns of parent-reported homework problems among ADHD-referred and non-referred children. School Psychology Quarterly, 21, 13-33. doi:10.1521/scpq. 2006.21.1.13.

Pressman, R. M., \& Imber, S. C. (2011). Relationship of children's daytime behavior problems with bedtime routines/practices: A family context and the consideration of faux-ADHD. American
Journal of Family Therapy, 39, 404-418. doi:10.1080/01926187. 2011.601218.

Prinstein, M. J., Heilbron, N., Guerry, J. D., Franklin, J. C., Rancourt, D., Simon, V., \& Spirito, A. (2010). Peer influence and nonsuicidal self injury: Longitudinal results in community and clinicallyreferred adolescent samples. Journal of Abnormal Child Psychology, 38, 669-682. doi:10.1007/s10802-010-9423-0.

Reinke, W. M., Herman, K. C., Petras, H., \& Ialongo, N. S. (2008). Empirically derived subtypes of child academic and behavior problems: Co-occurrence and distal outcomes. Journal of Abnormal Child Psychology, 36, 759-770. doi:10.1007/s10802007-9208-2.

Roane, B. M., \& Taylor, D. J. (2008). Adolescent insomnia as a risk factor for early adult depression and substance abuse. Sleep, 31, 1351-1356.

Roberts, R. E., Roberts, C. R., \& Chen, I. G. (2001). Functioning of adolescents with symptoms of disturbed sleep. Journal of Youth and Adolescence, 30, 1-18. doi:10.1023/A:1005230820074.

Roberts, R. E., Roberts, C. R., \& Chen, I. G. (2002). Impact of insomnia on future functioning of adolescents. Journal of Psychosomatic Research, 53, 561-569. doi:10.1016/S00223999(02)00446-4.

Roberts, R. E., Roberts, C. R., \& Xing, Y. (2011). Restricted sleep among adolescents: Prevalence, incidence, persistence, and associated factors. Behavioral Sleep Medicine, 9, 18-30. doi:10.1080/15402002.2011.533991.

Roehrs, T., \& Roth, T. (2008). Caffeine: Sleep and daytime sleepiness. Sleep Medicine Reviews, 12, 153-162. doi:10.1016/ j.smrv.2007.07.004.

Roenneberg, T., Kuehnle, T., Pramstaller, P. P., Ricken, J., Havel, M., Guth, A., \& Merrow, M. (2004). A marker for the end of adolescence. Current Biology, 14, R1038-R1039. doi:10.1016/j. cub.2004.11.039.

Rubens, S. L., Fite, P. J., Cooley, J. L., \& Canter, K. S. (2014). The role of sleep in the relation between community violence exposure and delinquency among Latino adolescents. Journal of Community Psychology, 42, 723-734. doi:10.1002/Jcop.21648.

Russo, P. M., Bruni, O., Lucidi, F., Ferri, R., \& Violani, C. (2007). Sleep habits and circadian preference in Italian children and adolescents. Journal of Sleep Research, 16, 163-169. doi:10. 1111/j.1365-2869.2007.00584.x.

Sadeh, A., Dahl, R. E., Shahar, G., \& Rosenblat-Stein, S. (2009). Sleep and the transition to adolescence: A longitudinal study. Sleep, 32, 1602-1609.

Sadeh, A., Gruber, R., \& Raviv, A. (2003). The effects of sleep restriction and extension on school-age children: What a difference an hour makes. Child Development, 74, 444-455. doi:10.1111/1467-8624.7402008.

Safron, D. J., Schulenberg, J. E., \& Bachman, J. G. (2001). Part-time work and hurried adolescence: the links among work intensity, social activities, health behaviors, and substance use. Journal of Health and Social Behavior, 42, 425-449.

Sarchiapone, M., Mandelli, L., Carli, V., Iosue, M., Wasserman, C., Hadlaczky, G., et al. (2014). Hours of sleep in adolescents and its association with anxiety, emotional concerns, and suicidal ideation. Sleep Medicine, 15, 248-254. doi:10.1016/j.sleep. 2013.11.780.

Scharfe, E., \& Eldredge, D. (2001). Associations between attachment representations and health behaviors in late adolescence. Journal of Health Psychology, 6, 295-307. doi:10.1177/135910530100 600303.

Schroeder, V. M., \& Kelley, M. L. (2009). Associations between family environment, parenting practices, and executive functioning of children with and without ADHD. Journal of Child and Family Studies, 18, 227-235. doi:10.1007/s10826-008-9223-0. 
Shanahan, L., Copeland, W. E., Angold, A., Bondy, C. L., \& Costello, E. J. (2014). Sleep problems predict and are predicted by generalized anxiety/depression and oppositional defiant disorder. Journal of the American Academy of Child and Adolescent Psychiatry, 53, 550-558. doi:10.1016/j.jaac.2013.12.029.

Shinkoda, H., Matsumoto, K., Park, Y. M., \& Nagashima, H. (2000). Sleep-wake habits of schoolchildren according to grade. Psychiatry and Clinical Neurosciences, 54, 287-289. doi:10. 1046/j.1440-1819.2000.00681.x.

Shochat, T., Cohen-Zion, M., \& Tzischinsky, O. (2014). Functional consequences of inadequate sleep in adolescents: A systematic review. Sleep Medicine Reviews, 18, 75-87. doi:10.1016/j.smrv. 2013.03.005

Shochat, T., Flint-Bretler, O., \& Tzischinsky, O. (2010). Sleep patterns, electronic media exposure and daytime sleep-related behaviours among Israeli adolescents. Acta Paediatrica, 99, 1396-1400. doi:10.1111/j.1651-2227.2010.01821.x.

Short, M. A., Gradisar, M., Lack, L. C., \& Wright, H. R. (2013a). The impact of sleep on adolescent depressed mood, alertness and academic performance. Journal of Adolescence, 36, 1025-1033. doi:10.1016/j.adolescence.2013.08.007.

Short, M. A., Gradisar, M., Lack, L. C., Wright, H. R., Dewald, J. F., Wolfson, A. R., \& Carskadon, M. A. (2013b). A cross-cultural comparison of sleep duration between US and Australian adolescents: The effect of school start time, parent-set bedtimes, and extracurricular load. Health Education and Behavior, 40, 323-330. doi:10.1177/1090198112451266.

Short, M. A., Gradisar, M., Wright, H., Lack, L. C., Dohnt, H., \& Carskadon, M. A. (2011). Time for bed: Parent-set bedtimes associated with improved sleep and daytime functioning in adolescents. Sleep, 34, 797-800. doi:10.5665/SLEEP.1052.

Sibley, M. H., Pelham, W. E, Jr, Molina, B. S., Gnagy, E. M., Waschbusch, D. A., Garefino, A. C., et al. (2012). Diagnosing ADHD in adolescence. Journal of Consulting and Clinical Psychology, 80, 139-150. doi:10.1037/a0026577.

Sisk, C. L., \& Foster, D. L. (2004). The neural basis of puberty and adolescence. Nature Neuroscience, 7, 1040-1047. doi:10.1038/ nn1326.

Sladek, M. R., \& Doane, L. D. (2015). Daily diary reports of social connection, objective sleep, and the cortisol awakening response during adolescents' first year of college. Journal of Youth and Adolescence. doi:10.1007/s10964-014-0244-2.

Sletten, T. L., Rajaratnam, S. M., Wright, M. J., Zhu, G., Naismith, S., Martin, N. G., \& Hickie, I. (2013). Genetic and environmental contributions to sleep-wake behavior in 12-year-old twins. Sleep, 36, 1715-1722. doi:10.5665/sleep.3136.

Smalley, S. L., McGough, J. J., Moilanen, I. K., Loo, S. K., Taanila, A., Ebeling, H., et al. (2007). Prevalence and psychiatric comorbidity of attention-deficit/hyperactivity disorder in an adolescent Finnish population. Journal of the American Academy of Child and Adolescent Psychiatry, 46, 1575-1583. doi:10. 1097/chi.0b013e3181573137.

Sondheim, S. (1984). Sunday in the Park with George: A musical. New York, NY: Revelation Music Pub. Corp. \& Rilting Music.

Sonuga-Barke, E. J., \& Castellanos, F. X. (2007). Spontaneous attentional fluctuations in impaired states and pathological conditions: A neurobiological hypothesis. Neuroscience and Biobehavioral Reviews, 31, 977-986. doi:10.1016/j.neubiorev. 2007.02.005

Spear, L. P. (2000). The adolescent brain and age-related behavioral manifestations. Neuroscience and Biobehavioral Reviews, 24, 417-463. doi:10.1016/S0149-7634(00)00014-2.

Stein, M. A., Weiss, M., \& Hlavaty, L. (2012). ADHD treatments, sleep, and sleep problems: Complex associations. Neurotherapeutics, 9, 509-517. doi:10.1007/s13311-012-0130-0.
Steinberg, L., \& Morris, A. S. (2001). Adolescent development. Annual Review of Psychology, 52, 83-110. doi:10.1146/annurev. psych.52.1.83.

Storch, E. A., Brassard, M. R., \& Masia-Warner, C. L. (2003). The relationship of peer victimization to social anxiety and loneliness in adolescence. Child Study Journal, 33, 1-18.

Storfer-Isser, A., Lebourgeois, M. K., Harsh, J., Tompsett, C. J., \& Redline, S. (2013). Psychometric properties of the Adolescent Sleep Hygiene Scale. Journal of Sleep Research, 22, 707-716. doi:10.1111/jsr.12059.

Sun, W. Q., Spruyt, K., Chen, W. J., Jiang, Y. R., Schonfeld, D., Adams, R., et al. (2014). The relation among sleep duration, homework burden, and sleep hygiene in Chinese school-aged children. Behavior Sleep Medicine, 12, 398-411. doi:10.1080/ 15402002.2013 .825837$.

Sung, V., Hiscock, H., Sciberras, E., \& Efron, D. (2008). Sleep problems in children with attention-deficit/hyperactivity disorder: Prevalence and the effect on the child and family. Archives of Pediatrics and Adolescent Medicine, 162, 336-342. doi:10. 1001/archpedi.162.4.336.

Susman, E. J., Dockray, S., Schiefelbein, V. L., Herwehe, S., Heaton, J. A., \& Dorn, L. D. (2007). Morningness/eveningness, morningto-afternoon cortisol ratio, and antisocial behavior problems during puberty. Developmental Psychology, 43, 811-822. doi:10. 1037/0012-1649.43.4.811.

Talbot, L. S., McGlinchey, E. L., Kaplan, K. A., Dahl, R. E., \& Harvey, A. G. (2010). Sleep deprivation in adolescents and adults: Changes in affect. Emotion, 10, 831-841. doi:10.1037/a0020138.

Tamm, L., Narad, M. E., Antonini, T. N., O’Brien, K. M., Hawk, L. W, Jr, \& Epstein, J. N. (2012). Reaction time variability in ADHD: A review. Neurotherapeutics, 9, 500-508. doi:10.1007/ s13311-012-0138-5.

Tavernier, R., \& Willoughby, T. (2014). Sleep problems: Predictor or outcome of media use among emerging adults at university? Journal of Sleep Research, 23, 389-396. doi:10.1111/jsr.12132.

Tavernier, R., \& Willoughby, T. (2015). A longitudinal examination of the bidirectional association between sleep problems and social ties at university: The mediating role of emotion regulation. Journal of Youth and Adolescence. doi:10.1007/ s10964-014-0107-x.

Taylor, D. J., Jenni, O. G., Acebo, C., \& Carskadon, M. A. (2005). Sleep tendency during extended wakefulness: Insights into adolescent sleep regulation and behavior. Journal of Sleep Research, 14, 239-244. doi:10.1111/j.1365-2869.2005.00467.x.

Teixeira, L. R., Fischer, F. M., de Andrade, M. M., Louzada, F. M., \& Nagai, R. (2004a). Sleep patterns of day-working, evening highschooled adolescents of São Paulo, Brazil. Chronobiology International, 21, 239-252. doi:10.1081/CBI-120037808.

Teixeira, L. R., Fischer, F. M., Nagai, R., \& Turte, S. L. (2004b). Teen at work: The burden of a double shift on daily activities. Chronobiology International, 21, 845-858. doi:10.1081/CBI200036878.

Teixeira, L. R., Lowden, A., Turte, S. L., Nagai, R., Moreno, C. R., Latorre, M. D. O. R., \& Fischer, F. M. (2007). Sleep and sleepiness among working and non-working high school evening students. Chronobiology International, 24, 99-113. doi:10.1080/ 07420520601139763.

Telzer, E. H., Fuligni, A. J., Lieberman, M. D., \& Galvan, A. (2013). The effects of poor quality sleep on brain function and risk taking in adolescence. Neuroimage, 71, 275-283. doi:10.1016/j. neuroimage.2013.01.025.

Terman, L. M., \& Hocking, A. (1913). The sleep of school children, its distribution according to age, and its relation to physical and mental activity. Journal of Educational Psychology, 4, 199-208. doi:10.1037/h0072166. 
Thakkar, V. G. (2013). Diagnosing the wrong deficit. The New York Times, p. SR1. http://www.nytimes.com/2013/04/28/opinion/sun day/diagnosing-the-wrong-deficit.html

Thomas, A. G., Monahan, K. C., Lukowski, A. F., \& Cauffman, E. (2015). Sleep problems across development: A pathway to adolescent risk taking through working memory. Journal of Youth and Adolescence. doi:10.1007/s10964-014-0179-7.

Thorleifsdottir, B., Bjornsson, J. K., Benediktsdottir, B., Gislason, T., \& Kristbjarnarson, H. (2002). Sleep and sleep habits from childhood to young adulthood over a 10-year period. Journal of Psychosomatic Research, 53, 529-537. doi:10.1016/S00223999(02)00444-0.

Tynjala, J., Kannas, L., Levalahti, E., \& Valimaa, R. (1999). Perceived sleep quality and its precursors in adolescents. Health Promotion International, 14, 155-166. doi:10.1093/heapro/14.2. 155.

Umlauf, M. G., Bolland, A. C., Bolland, K. A., Tomek, S., \& Bolland, J. M. (2015). The effects of age, gender, hopelessness, and exposure to violence on sleep disorder symptoms and daytime sleepiness among adolescents in impoverished neighborhoods. Journal of Youth and Adolescence. doi:10.1007/s10964-0140160-5.

Umlauf, M. G., Bolland, J. M., \& Lian, B. E. (2011). Sleep disturbance and risk behaviors among inner-city African-American adolescents. Journal of Urban Health, 88, 1130-1142. doi:10.1007/s11524-011-9591-4.

Van den Bulck, J. (2007). Adolescent use of mobile phones for calling and for sending text messages after lights out: Results from a prospective cohort study with a one-year follow-up. Sleep, 30, $1220-1223$.

Van Petegem, S., Beyers, W., Vansteenkiste, M., \& Soenens, B. (2012). On the association between adolescent autonomy and psychosocial functioning: Examining decisional independence from a self-determination theory perspective. Developmental Psychology, 48, 76-88. doi:10.1037/a0025307.

Vazsonyi, A. T., Harris, C., Terveer, A. M., Pagava, K., Phagava, H., \& Michaud, P. A. (2015). Parallel mediation effects by sleep on the parental warmth-problem behavior links: Evidence from national probability samples of Georgian and Swiss adolescents. Journal of Youth and Adolescence. doi:10.1007/s10964-0140167-y.

Vinha, D., Cavalcante, J. A., \& Andrade, M. M. M. (2002). Sleepwake patterns of student workers and non-workers. Biological Rhythm Research, 33, 417-426. doi:10.1076/brhm.33.4.417. 8803.

Wahlstrom, K. L. (2002). Accommodating the sleep patterns of adolescents within current educational structures: An uncharted path. In M. A. Carskadon (Ed.), Adolescent sleep patterns: Biological, social, and psychological influences (pp. 172-197). New York: Cambridge University Press.

Wahlstrom, K. L., Dretzke, B. J., Gordon, M. F., Peterson, K., Edwards, K., \& Gdula, J. (2014). Examining the impact of later high school start times on the health and academic performance of high school students: A multi-site study. St. Paul, MN: University of Minnesota.

Walther, C. A. P., Cheong, J., Molina, B. S. G., Pelham, W. E., Wymbs, B. T., Belendiuk, K. A., \& Pedersen, S. L. (2012). Substance use and delinquency among adolescents with childhood ADHD: The protective role of parenting. Psychology of Addictive Behaviors, 26, 585-598. doi:10.1037/A0026818.

Whitfield-Gabrieli, S., \& Ford, J. M. (2012). Default mode network activity and connectivity in psychopathology. Annual Review of Clinical Psychology, 8, 49-76. doi:10.1146/annurev-clinpsy032511-143049.

Whitford, T. J., Rennie, C. J., Grieve, S. M., Clark, C. R., Gordon, E., $\&$ Williams, L. M. (2007). Brain maturation in adolescence:
Concurrent changes in neuroanatomy and neurophysiology. Human Brain Mapping, 28, 228-237. doi:10.1002/hbm.20273.

Wilkinson, P., Kelvin, R., Roberts, C., Dubicka, B., \& Goodyer, I. (2011). Clinical and psychosocial predictors of suicide attempts and nonsuicidal self-injury in the Adolescent Depression Antidepressants and Psychotherapy Trial (ADAPT). American Journal of Psychiatry, 168, 495-501. doi:10.1176/appi.ajp.2010. 10050718.

Willcutt, E. G., Doyle, A. E., Nigg, J. T., Faraone, S. V., \& Pennington, B. F. (2005). Validity of the executive function theory of attention-deficit/hyperactivity disorder: A meta-analytic review. Biological Psychiatry, 57, 1336-1346. doi:10.1016/ j.biopsych.2005.02.006.

Winsler, A., Deutsch, A., Vorona, R. D., Payne, P. A., \& Szklo-Coxe, M. (2015). Sleepless in Fairfax: The difference one more hour of sleep can make for teen hopelessness, suicidal ideation, and substance use. Journal of Youth and Adolescence. doi:10.1007/ s10964-014-0170-3.

Wolfson, A. R., \& Carskadon, M. A. (1998). Sleep schedules and daytime functioning in adolescents. Child Development, 69, 875-887. doi:10.1111/j.1467-8624.1998.tb06149.x.

Wolfson, A. R., \& Carskadon, M. A. (2003). Understanding adolescents' sleep patterns and school performance: A critical appraisal. Sleep Medicine Reviews, 7, 491-506. doi:10.1016/ S1087-0792(03)90003-7.

Wolfson, A. R., \& Carskadon, M. A. (2005). A survey of factors influencing high school start times. NASSP Bulletin, 89, 47-66.

Wolfson, A. R., Spaulding, N. L., Dandrow, C., \& Baroni, E. M. (2007). Middle school start times: The importance of a good night's sleep for young adolescents. Behavioral Sleep Medicine, 5, 194-209. doi:10.1080/15402000701263809.

Wong, M. M., \& Brower, K. J. (2012). The prospective relationship between sleep problems and suicidal behavior in the National Longitudinal Study of Adolescent Health. Journal of Psychiatric Research, 46, 953-959. doi:10.1016/j.jpsychires.2012.04.008.

Wong, M. M., Brower, K. J., \& Zucker, R. A. (2009). Childhood sleep problems, early onset of substance use and behavioral problems in adolescence. Sleep Medicine, 10, 787-796. doi:10.1016/j. sleep.2008.06.015.

Worthman, C. M., \& Brown, R. A. (2007). Companionable sleep: Social regulation of sleep and cosleeping in Egyptian families. Journal of Family Psychology, 21, 124-135. doi:10.1037/08933200.21.1.124.

Xu, Z., Su, H., Zou, Y., Chen, J., Wu, J., \& Chang, W. (2012). Sleep quality of Chinese adolescents: distribution and its associated factors. Journal of Paediatrics and Child Health, 48, 138-145. doi:10.1111/j.1440-1754.2011.02065.x.

Yang, C. K., Kim, J. K., Patel, S. R., \& Lee, J. H. (2005). Age-related changes in sleep/wake patterns among Korean teenagers. Pediatrics, 115, 250-256. doi:10.1542/peds.2004-0815G.

Yen, C. F., King, B. H., \& Tang, T. C. (2010). The association between short and long nocturnal sleep durations and risky behaviours and the moderating factors in Taiwanese adolescents. Psychiatry Research, 179, 69-74. doi:10.1016/j.psychres.2009. 02.016.

Yip, T. (2015). The effects of ethnic/racial discrimination and sleep quality on depressive symptoms and self-esteem trajectories among diverse adolescents. Journal of Youth and Adolescence. doi:10.1007/s10964-014-0123-x.

Yoon, S. Y., Jain, U., \& Shapiro, C. (2012). Sleep in attention-deficit/ hyperactivity disorder in children and adults: Past, present, and future. Sleep Medicine Reviews, 16, 371-388. doi:10.1016/j. smrv.2011.07.001.

Zhou, H. Q., Shi, W. B., Wang, X. F., Yao, M., Cheng, G. Y., Chen, P. Y., \& Li, D. G. (2012). An epidemiological study of sleep quality in adolescents in South China: A school-based study. 
Child: Care, Health and Development, 38, 581-587. doi:10. 1111/j.1365-2214.2011.01300.x.

Stephen P. Becker, PhD is a Research Instructor of Pediatrics in the Center for ADHD within the Division of Behavioral Medicine and Clinical Psychology at Cincinnati Children's Hospital Medical Center (CCHMC). Dr. Becker's research focuses on understanding and treating ADHD and comorbid problems including sleep difficulties, internalizing symptoms, and sluggish cognitive tempo. His research has been funded by the Ohio Department of Mental Health, American Psychological Foundation/Council of Graduate Departments of Psychology, American Psychological Association, and Cincinnati Children's Research Foundation.

Joshua M. Langberg, PhD is an Associate Professor at Virginia Commonwealth University (VCU) in the Department of Psychology and Co-Director of the VCU Center for ADHD Research, Service, and Education. Dr. Langberg's research focuses on the identification of factors that predict the academic and socio-emotional functioning of youth with ADHD and on the development of interventions that address these factors. He has been principal investigator on three federally funded grants focused on improving the functioning of children and adolescents with ADHD (NIMH-R01 MH1082865; IES-R305A090305; IES-R305A130011).

Kelly C. Byars, PsyD is a Professor of Pediatrics at the University of Cincinnati College of Medicine in the Divisions of Behavioral Medicine and Pulmonary Medicine at Cincinnati Children's Hospital Medical Center (CCHMC). Dr. Byars is the clinical director of the Behavioral Sleep Medicine Program at CCHMC and is certified in Behavioral Sleep Medicine by the American Academy of Sleep Medicine. His research focus is pediatric insomnia and clinical outcomes within pediatric sleep medicine. Dr. Byars' research has been supported in part through funding from CCHMC, Autism Speaks/Autism Treatment Network, Autism Intervention Research Network in Physical Health (AIR-P), and Sepracor, Inc. 